\title{
Cirrus clouds in a global climate model with a statistical cirrus cloud scheme
}

\author{
M. Wang ${ }^{1,2}$ and J. E. Penner ${ }^{1}$ \\ ${ }^{1}$ Department of Atmospheric, Oceanic, and Space Sciences, University of Michigan, Ann Arbor, Michigan, USA \\ ${ }^{2}$ Atmospheric Science and Global Change Division, Pacific Northwest National Laboratory, Richland, Washington, USA
}

Received: 18 June 2009 - Published in Atmos. Chem. Phys. Discuss.: 7 August 2009

Revised: 30 May 2010 - Accepted: 12 June 2010 - Published: 21 June 2010

\begin{abstract}
A statistical cirrus cloud scheme that accounts for mesoscale temperature perturbations is implemented in a coupled aerosol and atmospheric circulation model to better represent both subgrid-scale supersaturation and cloud formation. This new scheme treats the effects of aerosol on cloud formation and ice freezing in an improved manner, and both homogeneous freezing and heterogeneous freezing are included. The scheme is able to better simulate the observed probability distribution of relative humidity compared to the scheme that was implemented in an older version of the model. Heterogeneous ice nuclei (IN) are shown to decrease the frequency of occurrence of supersaturation, and improve the comparison with observations at $192 \mathrm{hPa}$. Homogeneous freezing alone can not reproduce observed ice crystal number concentrations at low temperatures $(<205 \mathrm{~K})$, but the addition of heterogeneous IN improves the comparison somewhat. Increases in heterogeneous IN affect both high level cirrus clouds and low level liquid clouds. Increases in cirrus clouds lead to a more cloudy and moist lower troposphere with less precipitation, effects which we associate with the decreased convective activity. The change in the net cloud forcing is not very sensitive to the change in ice crystal concentrations, but the change in the net radiative flux at the top of the atmosphere is still large because of changes in water vapor. Changes in the magnitude of the assumed mesoscale temperature perturbations by $25 \%$ alter the ice crystal number concentrations and the net radiative fluxes by an amount that is comparable to that from a factor of 10 change in the heterogeneous IN number concentrations. Further improvements on the representation of mesoscale temperature perturbations, heterogeneous IN and the competition between homogeneous freezing and heterogeneous freezing are needed.
\end{abstract}

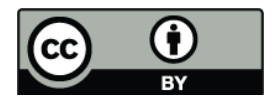

Correspondence to: M. Wang (minghuai.wang@pnl.gov)

\section{Introduction}

Cirrus clouds cover about 30\% of the Earth's area (Wang et al., 1996; Rossow and Schiffer, 1999; Wylie and Menzel, 1999) and are important in maintaining the global radiation balance (Ramanathan and Collins, 1991). They can form through either homogeneous freezing or heterogeneous freezing. Homogeneous freezing occurs through the freezing of liquid solutions such as sulfate droplets (Koop et al., 2000), and this usually occurs at low temperature and high relative humidity over ice $(\mathrm{RH} i)$. In contrast, heterogeneous freezing is mediated by insoluble solids (Pruppacher and Klett, 1997) or surfactant layers (Zobrist et al., 2007) that lower the energy barrier for the formation of an ice germ, and therefore requires lower supersaturation and can occur at higher temperatures. Aerosol particles that contribute such surfaces and undergo heterogeneous freezing are termed ice nuclei (IN). Mineral dust, carbonaceous, and metallic particles appear to be common heterogeneous IN (Chen et al., 1998; DeMott et al., 2003; Cziczo et al., 2004; 2009).

Homogeneous freezing is believed to be the primary mechanism for cirrus cloud formation in cold environments with high updraft velocities (e.g., Heymsfield and Sabin, 1989; Cantrell and Heymsfield, 2005), but the presence of heterogeneous IN can decrease the occurrence of homogeneous freezing because of the consumption of water vapor that prevents the formation of the high $\mathrm{RH} i$ needed (e.g., Demott et al., 1997; Liu and Penner, 2005). This preventive effect may significantly change cirrus cloud properties and humidity in the upper troposphere. Heterogeneous freezing from the small concentration of IN results in lower ice crystal number concentrations and larger ice crystal particles than those from homogeneous freezing, because of the dominance of particles that act as homogeneous freezing particles in the atmosphere. Jensen et al. (2008) suggested that it is likely that the observed presence of rather large ice crystals near the

Published by Copernicus Publications on behalf of the European Geosciences Union. 
tropical tropopause in very low concentrations results from ice nucleation on effective heterogeneous IN. Heterogeneous freezing may also change the frequency of occurrence of cirrus clouds because the required $\mathrm{RH} i$ is smaller and thus more frequent in occurrence (Jensen and Toon, 1997). Haag and Kärcher (2004) used a Lagrangian microphysical aerosolcloud model to show that the frequency of occurrence of thin cirrus clouds can be changed significantly as a result of the presence of a small number of IN at midlatitudes.

The calculation of the effect of heterogeneous IN on cirrus cloud properties is complicated by the fact that small scale dynamical processes play an important role in ice nucleation in the upper troposphere (e.g., Heymsfield, 1977; Ström et al, 1997; Kärcher and Ström, 2003; Haag and Kärcher, 2004; Jensen and Pfister, 2004; Hoyle et al., 2005). Small scale dynamical processes control the cooling rates within parcels that form cirrus clouds, which, together with the ambient temperature, determines whether heterogeneous or homogeneous freezing dominates. These processes are seen in measurements of vertical velocity and ice crystal concentration and ice water contents (Heymsfield, 1977) and in correlations between temperature anomalies induced by equatorial Kelvin waves and the occurrence of thin cirrus at the tropical tropopause (Immler et al., 2008). It has been suggested that cirrus formation is at least as sensitive to changes in dynamical forcing patterns as to changes in the aerosol size and number (Kärcher and Ström, 2003).

Global models have been used recently to study the effect of homogeneous and heterogeneous freezing on cirrus cloud properties (Lohmann and Kärcher, 2002; Hendricks et al., 2005; Lohmann et al., 2008; Liu et al., 2009). In these studies, the individual GCMs were updated to allow supersaturation with respect to ice, but cloud fraction was still diagnosed based on grid-mean relative humidity and the same humidity was assumed both inside and outside of cirrus clouds. This leads to a cloud fraction that is either 0 (if ice nucleation does not occur, and if ice crystals have not formed in the previous time step) or 1 (if ice crystals formed in the previous time step) when the grid mean RH $i$ is larger than $100 \%$. Partial cloud cover is only diagnosed when subsaturation subsequently occurs. The representation of subgrid-scale fluctuations of temperature, humidity, and cooling rates that are believed to control the cirrus microphysical formation process are highly simplified in these studies, since the effects of subgrid-scale fluctuations are only represented in the calculation of ice crystal number concentrations and cloud fraction only depends on the grid-mean relative humidity. These simplifications limit the ability to study aerosol indirect effects on cirrus clouds since effects on cloud fraction might actually dominate the total radiative effects of changing aerosol.

To address the inconsistency between the diagnosis of cloud fraction and the prediction of ice supersaturation, Tompkins et al. (2007) used a prognostic cloud fraction that is consistent with their predicted ice supersaturation in the European Centre for Medium-Range Weather Forecasts
(ECMWF) Integrated Forecast System. This scheme uses clear sky relative humidity to determine when ice freezing occurs and how much cloud fraction increases. However, this scheme has highly simplified ice microphysics (no ice crystal number is predicted). Moreover, this study assumed vapor saturation in cloudy air. In observations, both ice supersaturation and subsaturation can occur in cloudy air (Ström et al., 2003).

Kärcher and Burkhardt (2008, hereafter KB08) presented a statistical cloud scheme for non-convective cirrus formed by homogeneous freezing of supercooled aerosols, which treats cloud growth and decay based on a subgrid-scale distribution of temperature and total water. The scheme is based on separate probability distribution functions for total water in the clear-sky and cloudy sky portions of each grid. These distributions are based on in situ observations. Both sub- and supersaturation conditions with respect to ice are allowed to occur in cloud-free air and inside cirrus. This scheme was tested in a box model in KB08, which produced nucleated ice crystal number concentrations and ice crystal sizes in good agreement with observations.

In this study, an extension of the cirrus cloud scheme in KB08 is implemented in the updated version of NCAR CAM3 (Liu et al., 2007a, hereafter LIU07) which has been coupled with the LLNL/UMich IMPACT aerosol model (Wang et al., 2009). We have modified the KB08 scheme to include a simplified representation of both homogeneous and heterogeneous freezing. Anvil clouds from convective detrainment are also included and compete for water vapor with large scale cirrus clouds. The coupled model and the implementation of our extended version of KB08 are presented in Sect. 2, and model results in the case of homogeneous freezing only are shown in Sect. 3. The effects of changes in the number of assumed heterogeneous IN and changes to the assumed probability density function of the subgrid scale temperature perturbations are examined in Sect. 4. Finally, Sect. 5 summarizes our results and discusses directions for further improvement of the model.

\section{Model description and set-up of simulations}

The fully coupled IMPACT aerosol model and NCAR CAM3 model (Wang et al., 2009) is used in this study. The two model components of the coupled system are concurrently run in MPMD (Multiple Processors Multiple Data) mode to exchange aerosol fields and meteorological fields at each advection time step of the IMPACT model (Wang et al., 2009).

\subsection{The IMPACT global aerosol model}

In this study, the mass-only version of the Lawrence Livermore National Laboratory (LLNL)/University of Michigan IMPACT model was used, which predicts aerosol mass, but not number (Liu and Penner, 2002). We choose the 
mass-only version of the IMPACT model instead of the complete aerosol microphysics version used in Wang et al. (2009) because the mass-only version of the model is computationally fast which allowed us to run more sensitivity studies.

The mass-only version of IMPACT includes prognostic variables for sulfur and related species: dimethylsulfide (DMS), sulfur dioxide $\left(\mathrm{SO}_{2}\right)$, sulfate aerosol $\left(\mathrm{SO}_{4}^{2-}\right)$, and hydrogen peroxide $\left(\mathrm{H}_{2} \mathrm{O}_{2}\right)$; aerosols from biomass burning $\mathrm{BC}$ and organic matter (OM), fossil fuel $\mathrm{BC}$ and $\mathrm{OM}$, natural OM, aircraft BC (soot), mineral dust, and sea salt are also included. Sulfate aerosol is divided into three size bins with radii varying from $0.01-0.05 \mu \mathrm{m}, 0.05-0.63 \mu \mathrm{m}$ and $0.63-$ $1.26 \mu \mathrm{m}$, while mineral dust and sea salt are predicted in four bins with radii varying from $0.05-0.63 \mu \mathrm{m}, 0.63-1.26 \mu \mathrm{m}$, 1.26-2.5 $\mu \mathrm{m}$, and $2.5-10 \mu \mathrm{m}$. Carbonaceous aerosol (OM and $\mathrm{BC}$ ) is currently represented by a single submicron size bin. Emissions of primary particles and precursor gases, gasphase oxidation of precursor gases, aqueous-phase chemistry, rain-out and washout, gravitational settling, and dry deposition are treated. The mass-only version of the IMPACT aerosol model driven by meteorological fields from the NASA Data Assimilation Office (DAO) was included in the AEROCOM (http://nansen.ipsl.jussieu.fr/AEROCOM/) phase A and B evaluations (Kinne et al., 2006; Textor et al., 2006; Schulz et al., 2006), where it has been extensively compared with in situ and remotely sensed data for different aerosol properties.

Emissions of aerosol species and their precursors are described in detail in Wang et al. (2009). Anthropogenic sulfur emissions were from Smith et al. (2001, 2004), for the year 2000 (61.3 Tg S per year). Anthropogenic emissions of fossil fuel and biomass burning carbonaceous aerosols were from Ito and Penner (2005) for the year 2000, but adjusted as discussed in Wang et al. (2009). The sum of fossil fuel and biofuel $\mathrm{BC}$ and $\mathrm{OM}$ emissions were $5.8 \mathrm{Tg} \mathrm{BC}$ and 15.8 $\mathrm{Tg}$ OM per year, and the open biomass burning $\mathrm{BC}$ and $\mathrm{OM}$ emissions were 4.7 Tg BC and 47.4 Tg OM per year. Emissions of $\mathrm{BC}$ from aircraft were $0.0034 \mathrm{Tg}$ per year based on the fuel use model of Lee et al. (2005) with emission factors from AERO2K (Eyers et al., 2004). Natural emissions included volcanic $\mathrm{SO}_{2}$ (4.79 Tg S per year from Andres and Kasgnoc, 1998), marine dimethyl sulfide (DMS) (26.1 Tg S per year from Kettle and Andreae, 2000), OM from vegetation (14.5 Tg per year from Penner et al., 2001), and mineral dust provided by Ginoux (private communication, 2004) for the year 1998 based on the algorithm of Ginoux et al. (2001). Sea salt emissions (around $2560 \mathrm{Tg}$ per yr) were calculated online in the coupled CAM/IMPACT model using the method defined in Gong et al. (1997).

Prescribed size distributions from observations were used to calculate the number concentrations of sulfate, dust and soot particles that are used in the ice particle nucleation parameterization described in Sect. 2.2. Sulfate particles were assumed to have a lognormal size distribution with a mode radius of $0.02 \mu \mathrm{m}$, a geometric standard deviation of 2.3 and a density of $1840 \mathrm{~kg} / \mathrm{m}^{3}$ (Jensen et al., 1994). For soot particles emitted from the Earth's surface (i.e., biomass burning and fossil fuel combustion), we assumed a size distribution with a mode radius of $0.07 \mu \mathrm{m}$, a geometric standard deviation of 1.5 and a density of $1500 \mathrm{~kg} / \mathrm{m}^{3}$ (Pueschel et al., 1992). Aircraft soot has a much smaller size with a mode radius of $0.023 \mu \mathrm{m}$ and a geometric standard deviation of 1.5 (Petzold and Schröder, 1998). The size distribution of dust particles (Table S1 in the online supplemental material) is taken from De Reus et al. (2000).

\subsection{NCAR CAM3}

The NCAR Community Atmospheric Model (CAM3) is part of the Community Climate System Model 3 (CCSM3; Collins et al., 2006a, b). The model predicts both cloud liquid and cloud ice water (Boville et al., 2006). Cloud condensate detrained from deep and shallow convection is added into stratiform clouds. The gravitational settling as well as large-scale transport of cloud condensate is separately treated for cloud liquid and ice (Boville et al., 2006). However, in the standard CAM3, the partitioning between cloud liquid and cloud ice depends only on temperature $(T)$, and both the cloud droplet number and ice crystal number used in the cloud microphysics scheme are prescribed. Therefore, CAM3 is not able to represent a variety of processes (e.g., the Bergeron-Findeisen process, ice nucleation, droplet nucleation) that are important to the study of aerosol-cloud interactions.

The standard CAM3 version was updated in LIU07, by introducing a two-moment cloud microphysics scheme for cloud ice, in which number concentrations are predicted by a prognostic equation. The two-moment scheme treats ice nucleation, coagulation, evaporation, and melting. LIU07 also has a more physically-based representation of the liquid/ice partitioning in mixed-phase clouds than that used in the standard version of CAM3. This is accomplished by explicitly treating the liquid mass conversion to ice due to the depositonal growth of cloud ice at the expense of liquid water (the Bergeron-Findeisen process) using the scheme of Rotstayn et al. (2000). The cloud condensation and evaporation (CE) scheme of Zhang et al. (2003) which removes any supersaturation above that of liquid water in the standard CAM3 is only used for liquid water in warm $\left(T>0{ }^{\circ} \mathrm{C}\right)$ and mixedphase $\left(-35^{\circ} \mathrm{C}<T<0^{\circ} \mathrm{C}\right)$ clouds. With these modifications, supersaturation over ice is allowed in the upper troposphere. The coupled model with the ice cloud treatment in LIU07 has been used to study the effects of aerosols on cirrus clouds (Liu et al., 2009).

In LIU07, although supersaturation with respect to ice is allowed, cirrus cloud fraction is still diagnosed based on the grid-mean relative humidity, as described in Rasch and Kristjánsson (1998). This leads to an inconsistency between increases in cirrus cloud fraction and new cloud formation by ice nucleation. For example, new cloud 
formation by ice nucleation requires a $\mathrm{RH} i$ of about $125 \%$ (heterogeneous freezing) or 150\% (homogeneous freezing), but the cloud fraction in LIU07 begins to increase at a $\mathrm{RH} i$ of $90 \%$. This causes a large increase in the cirrus cloud fraction in LIU07 (56.8\%) compared to the standard CAM3 (32.2\%). Moreover, the grid-mean saturation ratio was used to initiate the freezing parameterization in LIU07, although the effect of mesoscale motions on ice crystal number concentrations were accounted for using a sub-grid variation of the updraft. Here, in order to treat cloud fraction and ice nucleation in an improved manner, an extended version of the statistical cirrus cloud scheme of KB08 was implemented in CAM3. This new scheme has subgrid-scale features for clear sky temperature and in-cloud total water, and is more realistic since it captures more of the sub-grid scale physics. Below we describe how the new scheme is incorporated into CAM3. Some important formulas other than those listed in this section appear in Appendix A, and readers are referred to KB08 for more details.

In the new cirrus cloud scheme, the specific humidity in both the clear sky areas $\left(q_{v e}\right)$ and cloudy areas $\left(q_{v c}\right)$ within a grid is predicted in the model. The specific humidity in the clear sky area is used to determine whether ice nucleation occurs and how much cloud fraction will increase as a result of any freezing, while the specific humidity in the cloudy part of the grid box is used to determine whether vapor deposition or sublimation occurs and the amount of cloud fraction decrease in the case of sublimation. The grid mean specific humidity $\left(q_{v}\right)$ is calculated as $a q_{v c}+(1-a) q_{v e}$, where $a$ is the cloud fraction. The grid mean specific humidity is advected.

Cloud growth is determined by the mean specific humidity in the clear part of a grid box using an assumed subgrid variation in the temperature profile. As shown in previous studies (KB08; Hoyle et al., 2005; Kärcher and Ström, 2003; Haag and Kärcher, 2004; Jensen and Pfister, 2004), the use of large scale temperature fluctuations alone is not sufficient for ice nucleation in cirrus clouds, so that the inclusion of mesoscale temperature fluctuations from small scale motions such as gravity waves are critical. These mesoscale temperature fluctuations cover horizontal length-scales 1-100 km (Ström et al., 1997; Bacmeister et al., 1999) and arise from a variety of sources including gravity waves released by mesoscale convective systems, high amplitude lee waves induced by high mountain ridges, or high amplitude lee waves induced in the area of jet streams and storm tracks (KB08). Even away from main source areas, there are persistent background of mesoscale temperature fluctuations driven by mesoscale gravity waves (Gary, 2006; 2008).

In the new cirrus cloud scheme, a probability density function (PDF) of temperature is used to represent mesoscale temperature perturbations in the clear sky portion of a grid. The PDF of temperature $\left(d P_{T} / d T\right)$ is assumed to be a constrained normal distribution with a mean temperature $\left(T_{0}\right)$ that is predicted by the GCM, and a standard deviation of $\delta T$ that is prescribed (see Eq. A1 in Appendix A). This normal distribution was shown to be an excellent approximation to the mesoscale distribution of temperature in background conditions in the middle latitudes of both hemispheres (KB08). The PDF of the temperature distribution is then transformed into a PDF of the saturation ratio $(S)\left(d P_{S} / d S\right)$ (Eq. A2) using the saturation vapor pressure over pure hexagonal ice (Murphy and Koop, 2005) and the mean specific humidity in the clear sky part of the grid $\left(q_{v e}\right)$. The portion of the distribution that is located above $S_{c r}$ is determinged by comparing the PDF of $S$ with the freezing threshold saturation ratio $\left(S_{c r}\right)$ :

$f\left(S>S_{c r}\right)=\int_{S_{c r}}^{S_{3+}} \frac{d P_{S}}{d S} d S$,

where $S_{3+}$ is the upper bound of the saturation ratio over which $d P_{S} / d S$ is defined (see Eq. A2). Ice crystals form when $d P s / d S$ extends above the freezing threshold. Cloud fraction increases from ice nucleation are defined as

$\Delta a=(1-a) f\left(S>S_{c r}\right)$

where $(1-a)$ is the clear sky fraction. The increase in the grid-mean ice crystal number concentration $\left(n_{i}\right)$ from ice nucleation is then

$\Delta n_{i}=N_{i} \Delta a$,

where $N_{i}$ is the in-cloud ice crystal number concentration from homogeneous and/or heterogeneous freezing, as discussed in detail later (Eqs. 6-11).

To calculate $N_{i}$, vertical velocities or cooling rates are needed, and are parameterized based on the probability distribution for $\delta T$. The mean cooling rate $\varpi$, induced by mesoscale temperature fluctuations, was approximated by

$\varpi\left[\mathrm{Kh}^{-1}\right]=8.2 \delta T[\mathrm{~K}]$,

in $\mathrm{KB} 08$; then the mean vertical velocity $(\bar{w})$ is deduced by assuming that the cooling takes place in a parcel lifting adiabatically. This cooling rate or vertical velocity is then used to calculate the ice crystal number concentration. For homogeneous freezing, the resulting ice crystal number density $N_{i \_ \text {homo }}$ was approximated as

$N_{i \_ \text {homo }} \approx 2 n(\bar{w})$,

where $n(\bar{w})$ is the ice crystal number concentration from the homogeneous freezing parameterization for the vertical velocity, $\bar{w}$ (see KB08).

The mesoscale temperature model from Gary $(2006 ; 2008)$ is used to predict $\delta T$. This temperature model is based on an analysis of more than 4000 aircraft flight hours taken by the Microwave Temperature Profiler in the altitude range 7$22 \mathrm{~km}$ and with a variety of underlying topography, spanning the latitude range $70^{\circ} \mathrm{S}$ to $80^{\circ} \mathrm{N}$. The model accounts for the seasonal, latitude, topographic, and altitude dependence of the temperature perturbation. For example, mesoscale 
temperature perturbations are greatest over mountainous terrain, are greater at polar latitudes during winter and increase with altitude in a systematic way. The altitude dependence in the Gary formula is consistent with gravity wave theory (Fritts and Alexander, 2003). The formula implemented in our model is based on Eqs. (4) and (5) in Gary (2008) for the $\mathrm{SH}$ and NH, respectively, but adds an altitude term (Eq. (3) in Gary, 2008) and a topography term (Eq. (6) in Gary, 2006). At $58.85 \mathrm{hPa}$, the Gary formula gives a $\delta T$ in the range of 0.2 to $1.0 \mathrm{~K}$. The mean cooling rate is calculated from the temperature perturbation using Eq. (4) and the mean number concentration for homogeneous freezing relies on Eq. (5).

We also extended the KB08 formulation to include the competition between homogeneous and heterogeneous freezing. When homogeneous freezing is the only freezing mode, ice crystal number concentration from ice freezing $\left(N_{i}\right.$ homo $)$ and the threshold freezing saturation ratio $\left(S_{c r} \_\right.$homo $)$are parameterized based on Liu and Penner (2005), and used in Eqs. (2) and (3) (with $N_{i}$ homo adjusted by a factor of 2, see Eq. 5). We rely on the parcel model results of Liu and Penner (2005) to account for the competition between homogeneous freezing and heterogeneous freezing. Liu and Penner (2005) showed that when the heterogeneous IN concentration $\left(N_{\text {in }}\right)$ is larger than a critical IN number concentration $\left(N_{\text {in_cr }}\right)$, the ice crystal number concentration is determined by heterogeneous freezing and there is a transition region for heterogeneous IN number concentrations from $N_{\text {in_cr }} / 10$ to $N_{\text {in_cr }}$, in which ice crystal number concentrations gradually decrease from those determined by homogeneous freezing to those determined by heterogeneous freezing. When heterogeneous IN concentrations are lower than $N_{\text {in } \_c r} / 10$, ice crystal number concentrations are determined by homogeneous freezing. Thus the cloud fraction increase and ice crystal number concentration increase in the scenario with both homogeneous and heterogeneous freezing was defined as:

$$
\begin{aligned}
& \Delta a=(1-a) f\left(S>S_{c r \_ \text {homo }}\right), \\
& \Delta n_{i}=N_{i \_ \text {homo }} \Delta a, \text { when } N_{\text {in }}<N_{\text {in } \_c r} / 10 \\
& \Delta a=(1-a) f\left(S>S_{c r \_ \text {homo }}\right), \\
& \Delta n_{i}=N_{i \_ \text {homhet }} \Delta a, \text { when } N_{\text {in } \_c r} / 10<N_{\text {in }}<N_{\text {in } \_c r}
\end{aligned}
$$

and

$$
\begin{aligned}
& \Delta a=(1-a) f\left(S>S_{c r \_ \text {hete }}\right) \\
& \Delta n_{i}=N_{i \_ \text {hete }} \Delta a+N_{i \_ \text {homo }}(1-a) f\left(S>S_{c r \_ \text {homo }}\right), \\
& \text { when } N_{\text {in }}>N_{\text {in_cr }} .
\end{aligned}
$$

where $S_{c r \text { hete }}$ is the heterogeneous freezing threshold saturation ratio, $N_{i}$ hete is the ice crystal number concentration from heterogeneous freezing, and $N_{i \text { homhet }}$ is the ice crystal number concentration in the transition region which takes into account the effects of heterogeneous IN on ice crystal number concentrations from homogeneous freezing. $S_{c r \text { hete }}, N_{i \text { hete }}$, and $N_{i \text { homhet }}$ are calculated based on Eqs. (4.4), (4.7), and (4.11) in Liu and Penner (2005), respectively. $N_{\text {in_cr }}$ derived by Gierens (2003) is used. $N_{i \_ \text {homo }}$ (increased by a factor of 2, see Eq. 5), $N_{\text {in_cr }}, N_{i \_ \text {homhet }}$ and $N_{i \text { hete }}$ are evaluated at the average updraft velocity $\bar{w}$. The ice number from heterogeneous freezing is not multiplied by a factor of 2, since the factor of 2 that is applied for homogeneous freezing is primarily used to account for the nonlinear dependence of ice crystal number concentrations on vertical velocity and since the number of ice crystals formed in an environment dominated by heterogeneous freezing is not as sensitive to changes in vertical velocity as those from homogeneous freezing.

An initial ice crystal mass of $10^{-12} \mathrm{~kg}$ is assumed for newly formed ice particles. This is a simplification of the treatment used in KB08. Because the time step of the GCM is large (about half an hour), all supersaturation in newly formed clouds is usually removed and the in-cloud saturation ratio with respect to ice is close to 1.0 , which makes the initial ice crystal mass not important. After the removal of the initial ice crystal mass, the remaining water vapor in the new clouds is then moved into the cloudy portion of the grid and the in-cloud specific humidity $q_{v c}$ is updated.

In cloudy areas, ice crystals grow through vapor deposition and the in-cloud water vapor $q_{v c}$ is transferred to ice crystals via gas phase diffusion,

$\left(\Delta q_{v c}\right)_{\mathrm{dep}}=-\left(q_{v c}-q_{\mathrm{sat}}\right)\left\{1-\exp \left(-\tau / \tau_{s}\right)\right\}$,

where $q_{\text {sat }}$ is the saturation specific humidity, $\tau$ is the time step, and $\tau_{s}$ is the instantaneous relaxation time scale (see Eq. A7), which determines how long the supersaturation $\left(S_{c r}-1\right)$ lasts after freezing. The change in the grid averaged ice water content through vapor deposition is $-a\left(\Delta \mathrm{q}_{v c}\right)_{\mathrm{dep}}$.

Cloud decay is determined by the in-cloud specific humidity, ice water content, and a PDF of the in-cloud total water mass mixing ratio ( $q_{\text {totc }}$ ) (see Eq. A9). In-cloud specific humidity has a homogeneously distributed PDF in the form of a delta function, $\delta\left(\mathrm{q}-\mathrm{q}_{v c}\right)$. Therefore, the PDF of the total water mass mixing ratio $\left(d P_{\text {qtot }} / d q_{\text {tot }}\right)$ is determined by the PDF of the in-cloud ice water content (see Eq. A8). Cloud decay occurs when the in-cloud air becomes subsaturated (incloud saturation ratio $S_{c}<1$ ) due to warming or drying. This subsaturation leads to the sublimation of ice crystals. The smallest ice crystals experiencing the highest subsaturations will completely sublimate first. The sublimation $\left(\Delta q_{v c}\right)$ is calculated based on Eq. (12) when $q_{v c}$ is less than $q_{\text {sat }}$. The cloud fraction decrease is determined by the portion of the PDF of ice water in which ice water is less than $\Delta q_{v c}$, and is calculated as:

$$
\begin{aligned}
& \Delta a=a \int_{q_{v c}}^{q_{v c}+\Delta q_{v c}} \frac{d P_{q_{\mathrm{totc}}}}{q_{\mathrm{totc}}} d q_{\mathrm{totc}} \\
& =-\operatorname{erf}(\xi) a, \xi=a \Delta q_{v c} /\left(q_{i} \pi^{0.5}\right),
\end{aligned}
$$


where $\operatorname{erf}(x)$ is the error function (see Eq. A5). The change in ice water content is determined by the following formula:

$\Delta q_{i}=-q_{i}\left[1-\exp \left(-\xi^{2}\right)+\pi^{0.5} \xi\{1-\operatorname{erf}(\xi)\}\right]$.

The decrease in ice crystal number concentration $\left(\Delta \mathrm{n}_{i}\right)$ is assumed to be proportional to the cloud fraction decrease, and is calculated as

$\Delta n_{i}=n_{i} \Delta a / a$.

In the standard version of CAM3, detrained cloud water is added to the large scale clouds along with the convective cloud fraction $\left(a_{c o n v}\right)$ which is diagnosed from convective mass fluxes (Boville et al., 2006). This is the case for warm clouds and mixed-phase clouds treated in this study, where cloud droplet and ice crystal number from detrained cloud water are also added into the large scale clouds with assumed volume mean radii (see the on-line supplemental material for details). For cirrus clouds, detrained cloud ice mass and crystal number are still added to the large scale clouds in the same way as in warm and mixed-phase clouds. But since cloud fraction in cirrus clouds is prognostic rather than diagnostic, cloud fraction increases from the convective source are calculated at each time step according to:

$(\Delta a)_{\mathrm{conv}}=(1-a) a_{\mathrm{conv}}$,

The factor $1-a$ in Eq. (16) appears because convective air detrains simultaneously into cloud-free air, as well as into already existing clouds, ensuring realistic limits at zero cloud cover and at cloud cover 1 , following the same assumption as in Tiedtke (1993). This new cloud is assumed to be at saturation with respect to ice (the same assumption is used in the standard CAM3, see Boville et al., 2006), which also sets the upper limit of the cloud fraction increase from convective cloud as $(1-a) q_{v e} / q_{\text {sat }}$ (i.e., the water vapor in the new cloud $\left((\Delta \mathrm{a})_{\text {conv }} q_{\text {sat }}\right)$ will not exceed the available water vapor in the clear $\left.\left.\operatorname{sky}(1-a) q_{v e}\right)\right)$. After the cloud fraction from convective clouds is updated, the in-cloud specific humidity is calculated as

$q_{v c}=\left(q_{v c} a+q_{\mathrm{sat}}(\Delta a)_{\mathrm{conv}}\right) /\left(a+(\Delta a)_{\mathrm{conv}}\right)$.

In the standard CAM3 and the version updated in LIU07, only the grid-mean specific humidity $(q)$ is predicted, using:

$\frac{\partial q}{\partial t}=A_{q}-Q+E_{r}$

where $A_{q}$ is the tendency of water vapor from processes other than large-scale condensation and evaporation of cloud and rain water, $Q$ is the net condensation rate, and $E_{r}$ is the evaporation of rain water. In order to predict the in-cloud specific humidity $\left(q_{v c}\right)$, we assume that $A_{q}$ is uniformly applied to the whole model grid cell, which is also the assumption made in the condensation-evaporation scheme in CAM3 (Zhang et al., 2003). The in-cloud specific humidity is then predicted together with cloud fraction growth (from both large scale and convective clouds), decay, and in-cloud vapor deposition/evaporation.

Both cloud ice mass and ice crystal number are advected as in LIU07. The tendencies of cloud ice mass $\left(A_{q i}\right)$ and ice crystal number $\left(A_{n i}\right)$ from processes other than large-scale formation or decay of clouds, detrainment, and sedimentation are also assumed to be uniformly applied to the whole model grid cell. It is assumed that the part of these tendencies that falls into the clear sky portion of the grid is evaporated (the same assumption as that used in Zhang et al., 2003). For simplicity, the cloud fraction predicted here is not advected (see Sect. 5 for further discussion of the effects of this simplification). As a consequence, cloud ice may be advected to grids that have no cloud fraction or partial cloud fraction. If this is the case, the cloud ice that is advected into the clear sky portion of the grid will be evaporated.

The treatment of ice crystal sedimentation follows that in the NCAR CAM3 model (Boville et al., 2006). Sedimenting particles sublimate if they fall into the cloud free portion of a layer. A maximum cloud overlap is assumed, so particles only sublimate if the cloud fraction is larger in the layer above. Since the model does not treat partial cloud fraction in the vertical direction, sedimentation is assumed to change ice crystal number concentration but not cloud fraction.

The new cirrus cloud scheme described here is only applied to clouds with temperatures colder than $-35^{\circ} \mathrm{C}$. For clouds warmer than $-35^{\circ} \mathrm{C}$, the treatment in LIU07 is used, but with some updates. These include a prognostic liquid droplet number equation that takes into account droplet activation, coagulation, evaporation, and freezing, which, together with the ice cloud treatment, consists of a complete set of equations for the two-moment treatment of cloud microphysics in NCAR CAM3. Also the direct conversion from liquid to ice in mixed-phase clouds which was used in simulating observed clouds in the Mixed-Phase Arctic Cloud Experiment (M-PACE) in a single column model (Liu et al., 2007b) and in a short-range weather forecasting approach (Xie et al., 2008) was included. These updates are described in the on-line supplement.

\subsection{Set-up of simulations and experimental design}

The simulations are described in Table 1. In "HOM", only homogeneous freezing on sulfate particles was considered. Three cases are used to study how cirrus cloud properties change with different IN concentrations. Since the freezing capabilities of different aerosol particles acting as IN are poorly understood, we simply use sensitivity tests to study the effects of different aerosols as IN on cirrus clouds. The same temperature perturbation as that used in the HOM case is applied, but with $1 \%, 10 \%$, and $100 \%$ of soot and dust particles acting as heterogeneous IN in HMHT_0.01IN, HMHT_0.1IN, and HMHT_1IN, respectively. The $1 \%$ value is consistent with the report by Seifert et al. (2003) that 
Table 1. Descriptions of simulations.

\begin{tabular}{ll}
\hline Case names & Descriptions \\
\hline HOM & Homogeneous freezing on sulfate particles. \\
HMHT_0.01IN & Same as HOM, but 1\% of soot and dust particles are included to act as heterogeneous IN. \\
HMHT_0.1IN & Same as HMHT_0.01IN, but $10 \%$ of soot and dust particles acts as heterogeneous IN. \\
HMHT_1IN & Same as HMHT_0.01IN, but 100\% of soot and dust particles act as heterogeneous IN. \\
HMHT_0.75dT & Same as HMHT_0.01IN, but temperature perturbation is decreased by 25\%. \\
HMHT_1.25dT & Same as HMTH_0.01IN, but temperature perturbation is increased by 25\%. \\
\hline
\end{tabular}

scavenging ratios were $<1 \%$ in the INCA campaign. The $100 \%$ value represents the case where soot and dust particles are efficient IN, as assumed in some previous modeling studies (e.g., Hendricks et al., 2005). Two additional cases are used to study how different temperature perturbations will change cirrus cloud properties. These two cases have the same IN concentration as in the HMHT_0.01IN case, but temperature perturbations have been decreased/increased by $25 \%$ in HMHT_0.75dT and HMHT_1.25dT, respectively. These results are also compared with the results from the standard version of CAM3 (CAM3) and LIU07. In LIU07, the treatment of ice clouds does not include the subgrid parameterization of supersaturation and cloud fraction used here and the cloud droplet number concentrations in liquid clouds are prescribed as in the standard version of CAM3.

We used 26 vertical levels and a horizontal resolution of $2 \times 2.5$ degrees for both the CAM3 and IMPACT models in this study. The time step for CAM3 was $30 \mathrm{~min}$, and the time step for advection in IMPACT was $1 \mathrm{~h}$. The finite volume dynamical core was chosen for CAM3. All simulations used climatological sea surface temperatures, and the coupled model was integrated for 5 years after an initial spin-up time of four months.

\section{Model results for the HOM case}

Tables 2 and 3 show the annual global mean values for several parameters in our simulations along with results from the standard CAM3 and observations. The liquid water path in the HOM simulation is $78 \mathrm{~g} / \mathrm{m}^{2}$, much less than that simulated in LIU07 and in the standard CAM3, and close to the observed range of $50-84 \mathrm{~g} / \mathrm{m}^{2}$; this value is also close to that simulated by Gettleman et al. (2008) in a modified version of CAM3 that also includes a two moment cloud microphysics treatment $\left(74 \mathrm{~g} / \mathrm{m}^{2}\right)$. The large decrease in liquid water path compared with that in LIU07 is mainly caused by the treatment of the Bergeron-Findeisen process where ice crystals grow at the expense of liquid droplets. As noted above, this treatment has been changed to that of Xie et al. (2008) where a direct conversion from liquid to ice is assumed. This change results in a larger conversion rate from liquid to ice in mixed-phase clouds (see the on-line supplement). Be- cause ice crystals are more efficient at producing precipitation, the inclusion of this process in the manner outlined here decreases the liquid water path significantly compared to that in LIU07.

In our simulations, cloud-top quantities (liquid droplet and ice crystal number and radius) are estimated as seen by satellite instruments using a modification of the maximum/random cloud overlap assumption that is used in the radiative transfer calculations in the NCAR CAM3 (Collins et al., 2001) to obtain the two-dimensional field (Quaas et al., 2004). Cloud top quantities are sampled only for clouds with optical depth larger than 0.3 , and are also only sampled once per day at the over pass time of MODIS Aqua satellite (01:30 p.m., local time). For cloud droplet radius, the samples are limited to warm clouds (cloud top temperature larger than $273.16 \mathrm{~K}$ ), and for ice crystal radius, the samples are limited to cold cirrus clouds (cloud top temperature less than $238.16 \mathrm{~K}$ ). Using this procedure, our simulated cloud top droplet effective radius for warm clouds (cloud top temperature $>273.16 \mathrm{~K}$ ) is $11.1 \mu \mathrm{m}$, which matches well with AVHRR observations $(11.40 \mu \mathrm{m})$, but is lower than that from MODIS observations $(15.7 \mu \mathrm{m})$. The column integrated droplet number concentration averaged over $50^{\circ} \mathrm{S}-50^{\circ} \mathrm{N}$ is $2.3 \times 10^{10} / \mathrm{m}^{2}$, and is underestimated compared with AVHRR observations $\left(4.0 \times 10^{10} / \mathrm{m}^{2}\right)$.

The ice water path is $21 \mathrm{~g} / \mathrm{m}^{2}$, which is comparable to satellite observations (Fig. 18 in Waliser et al., 2009). The column integrated ice crystal number concentration is about $0.09 \times 10^{10} / \mathrm{m}^{2}$, which is smaller than that predicted by Lohmann et al. (2007) $\left(0.1-0.7 \times 10^{10} / \mathrm{m}^{2}\right)$. The large difference mainly comes from the difference in the treatments of mixed-phase clouds. In our model, mineral dust particles are the only contact freezing IN, but in Lohmann et al. (2007), both mineral dust and soot particles act as contact freezing ice nuclei. Moreover, Lohmann et al. (2007) included an immersion freezing scheme that has a freezing fraction of 1 for dust particles at temperatures lower than $-15^{\circ} \mathrm{C}$ and has a freezing fraction of 1 for soot particles at temperatures lower than $-25^{\circ} \mathrm{C}$ (Fig. 10 in Phillips et al., 2008). The simulated ice crystal number concentration in mixed-phase clouds in our model is generally less than $1 / \mathrm{L}$, which is comparable to observations from the M-PACE field experiments 
Table 2. Annual global mean cloud properties and their interannual variations (standard deviations).

\begin{tabular}{|c|c|c|c|c|c|c|c|c|c|}
\hline & $\mathrm{HOM}$ & HMHT_0.01IN & HMHT_0.1IN & HMHT_1IN & HMHT_1.25T & HMHT_0.75T & LIU07 & CAM3 & Obs \\
\hline LWP $^{\mathrm{a}}$ & $78.21 \pm 0.36$ & $76.74 \pm 0.36$ & $75.38 \pm 0.12$ & $80.97 \pm 0.34$ & $77.32 \pm 0.55$ & $75.67 \pm 0.50$ & 141 & 121 & $50-87$ \\
\hline $\mathrm{IWP}^{\mathrm{b}}$ & $20.94 \pm 0.05$ & $21.02 \pm 0.04$ & $21.07 \pm 0.09$ & $21.46 \pm 0.04$ & $21.06 \pm 0.06$ & $20.91 \pm 0.11$ & 21.8 & 15.6 & 26.7 \\
\hline$N_{d}^{\mathrm{c}}$ & $2.31 \pm 0.020$ & $2.26 \pm 0.015$ & $2.22 \pm 0.013$ & $2.41 \pm 0.014$ & $2.28 \pm 0.015$ & $2.22 \pm 0.012$ & $\#$ & $\#$ & 4 \\
\hline$N_{i}^{d}$ & $0.088 \pm 0.006$ & $0.062 \pm 0.004$ & $0.023 \pm 0.002$ & $0.050 \pm 0.003$ & $0.094 \pm 0.009$ & $0.041 \pm 0.004$ & 0.027 & \# & \# \\
\hline$r_{\mathrm{effl}}^{c^{c}}$ & $11.09 \pm 0.01$ & $11.09 \pm 0.02$ & $11.09 \pm 0.02$ & $11.07 \pm 0.01$ & $11.08 \pm 0.00$ & $11.11 \pm 0.00$ & $\#$ & \# & $11.4-15.7$ \\
\hline$r_{\mathrm{effi}}^{\mathrm{d}}$ & $47.54 \pm 0.45$ & $55.10 \pm 0.26$ & $48.21 \pm 0.25$ & $41.51 \pm 0.30$ & $52.88 \pm 0.73$ & $57.05 \pm 0.37$ & \# & \# & 25.21 \\
\hline$N_{\text {itop }}^{\mathrm{d}}$ & $0.87 \pm 0.04$ & $0.61 \pm 0.02$ & $0.13 \pm 0.01$ & $0.42 \pm 0.03$ & $0.87 \pm 0.04$ & $0.37 \pm 0.02$ & \# & \# & \# \\
\hline $\mathrm{TCC}^{\mathrm{e}}$ & $66.07 \pm 0.15$ & $66.83 \pm 0.09$ & $67.92 \pm 0.13$ & $68.18 \pm 0.11$ & $66.59 \pm 0.11$ & $67.31 \pm 0.17$ & 77.90 & 58.6 & $65-67$ \\
\hline $\mathrm{TCCHGH}^{\mathrm{e}}$ & $35.41 \pm 0.14$ & $38.30 \pm 0.12$ & $39.94 \pm 0.11$ & $39.67 \pm 0.13$ & $37.61 \pm 0.17$ & $39.39 \pm 0.17$ & 56.80 & 32.2 & 21 \\
\hline TCCLOW $^{\mathrm{e}}$ & $44.59 \pm 0.13$ & $44.22 \pm 0.09$ & $43.83 \pm 0.14$ & $45.22 \pm 0.12$ & $44.40 \pm 0.16$ & $44.05 \pm 0.13$ & \# & $\#$ & $\#$ \\
\hline
\end{tabular}

a The liquid water path (LWP, g/m²) observations are from SSM/I (for the years 1987-1994, Ferraro et al., 1996; for August 1993 and January 1994, Weng and Grody, 1994; and for August 1987 and February 1988, Greenwald et al., 1993) and ISCCP for the year 1987 (Han et al., 1994). SSM/I data are restricted to oceans.

${ }^{\mathrm{b}}$ Ice water path (IWP, $\mathrm{g} / \mathrm{m}^{2}$ ) has been derived from ISCCP data for the years 1983-2000 (Storelvmo et al., 2008).

$\mathrm{c}^{\mathrm{c}} \mathrm{N}_{d}$ and $\mathrm{N}_{i}$ refer to the vertically integrated cloud droplet and ice crystal number concentration $\left(10^{10} / \mathrm{m}^{2}\right)$, and $r_{\text {eff }}(\mu \mathrm{m})$ refers to the cloud top effective radius. Observations of $\mathrm{N}_{d}$ are obtained from ISCCP for the year 1987 (Han et al., 1998) and observations of $r_{\text {effl }}$ are obtained from ISCCP for the year 1987 (Han et al, 1994 ) and from MODIS (version 4) for the year 2001 (Platnick et al., 2003), and are limited to $50^{\circ} \mathrm{N}$ to $50^{\circ} \mathrm{S}$.

d $r_{\text {effi }}$ and $\mathrm{N}_{\text {itop }}$ refer to ice crystal radius and number at the top of cirrus clouds, respectively. Observations of $r_{\text {effi }}$ are from MODIS data (version 4 ) for the year 2001.

e Total cloud cover (TCC) was obtained from ISCCP for the years 1983-2001 (Rossow and Schiffer, 1999) and MODIS data for the years 2001-2004 (Platnick, 2003). High cloud cover (TCCHGH) was obtained from ISCCP data for the years 1983-2001. TCCLOW refers to low level cloud cover.

Table 3. Annual global mean shortwave cloud forcing ( $\mathrm{SWCF}, \mathrm{W} / \mathrm{m}^{2}$ ), longwave cloud forcing $\left(\mathrm{LWCF}, \mathrm{W} / \mathrm{m}^{2}\right.$ ), net cloud forcing $\left(\mathrm{CF}, \mathrm{W} / \mathrm{m}^{2}\right)$, total precipitation (Ptot, $\mathrm{mm} /$ day), convective precipitation (Pcov, $\mathrm{mm} / \mathrm{day}$ ), water vapor mass $\left(\mathrm{WVM}, \mathrm{kg} / \mathrm{m}^{2}\right.$ ), net incoming radiation at the top of the atmosphere $\left(\mathrm{FNT}, \mathrm{W} / \mathrm{m}^{2}\right.$ ), and clear sky net long wave radiation at the top of the atmosphere (FLNTC, W/m², negative values mean outgoing) and their interannual variations (standard deviations).

\begin{tabular}{|c|c|c|c|c|c|c|c|c|c|}
\hline & $\mathrm{HOM}$ & HMHT_0.01IN & HMHT_0.1IN & HMHT_1IN & HMHT_1.25T & HMHT_0.75T & LIU07 & CAM3 & Obs \\
\hline SWCF $^{\mathrm{a}}$ & $-52.30 \pm 0.11$ & $-51.02 \pm 0.21$ & $-50.29 \pm 0.12$ & $-54.27 \pm 0.13$ & $-51.61 \pm 0.25$ & $-50.33 \pm 0.28$ & -59.1 & -54.6 & -47 to -54 \\
\hline $\mathrm{LWCF}^{\mathrm{a}}$ & $27.28 \pm 0.09$ & $25.90 \pm 0.10$ & $25.37 \pm 0.02$ & $29.64 \pm 0.05$ & $26.75 \pm 0.12$ & $25.04 \pm 0.08$ & 31.9 & 30.6 & 29 to 30 \\
\hline $\mathrm{CF}$ & $-25.02 \pm 0.05$ & $-25.12 \pm 0.13$ & $-24.92 \pm 0.11$ & $-24.63 \pm 0.10$ & $-24.85 \pm 0.27$ & $-25.28 \pm 0.22$ & -27.2 & -24.0 & $\#$ \\
\hline Pcov & $1.92 \pm 0.005$ & $1.95 \pm 0.005$ & $2.00 \pm 0.007$ & $1.86 \pm 0.005$ & $1.93 \pm 0.003$ & $1.98 \pm 0.002$ & $\#$ & $\#$ & $\#$ \\
\hline $\mathrm{WVM}^{\mathrm{c}}$ & $24.48 \pm 0.05$ & $24.15 \pm 0.04$ & $23.88 \pm 0.04$ & $24.97 \pm 0.04$ & $24.37 \pm 0.04$ & $24.02 \pm 0.04$ & \# & \# & 22.80 \\
\hline FNT & $3.21 \pm 0.32$ & $2.63 \pm 0.28$ & $1.69 \pm 0.04$ & $3.37 \pm 0.21$ & $3.23 \pm 0.34$ & $2.19 \pm 0.43$ & \# & \# & $\#$ \\
\hline
\end{tabular}

a The shortwave (SWCF) and longwave cloud forcing (LWCF) observations are taken from ERBE for the years 1985-1989 (Kiehl and Trenberth, 1997) and CERES for the years 2000-2005 (http://science.larc.nasa.gov/ceres). b Total precipitation $\left(P_{\text {tot }}\right)$ observations are taken from the Global Precipitation Data Set for the years 1979-2002 (http: //precip.gsfc.nasa.gov). ${ }^{c}$ Water vapor mass (WVM) data is from MODIS for the years 2001-2004 (King et al., 2003).

(McFarquhar et al., 2007). The average cloud top ice crystal radius for cold cirrus clouds (cloud top temperature less than $-35^{\circ} \mathrm{C}$ ) is $47.5 \mu \mathrm{m}$, larger than that observed by the MODIS instrument $(25.21 \mu \mathrm{m})$.

The total cloud fraction is $66 \%$ which is comparable to that observed from ISCCP and MODIS (65-67\%), but is lower than that from HIRS (75\%). The high level cloud fraction is $35 \%$, which is comparable to that observed by HIRS (33\%) but larger than that from ISCCP $(21 \%)$. HIRS measures more optically thin clouds (with an optical depth detection limit of around 0.1) than those from ISCCP (with an optical depth detection limit of around 0.3), and is more representative for high level clouds (Wylie and Menzel, 1999). The new cirrus cloud scheme simulates significantly fewer high clouds than LIU07 and improves the model results compared with ob- servations. Shortwave cloud forcing is $-52 \mathrm{~W} / \mathrm{m}^{2}$, which is comparable to ERBE $\left(-54 \mathrm{~W} / \mathrm{m}^{2}\right)$ and CERES $\left(-47 \mathrm{~W} / \mathrm{m}^{2}\right)$ observations. Long wave cloud forcing is $27 \mathrm{~W} / \mathrm{m}^{2}$, which is also comparable to ERBE $\left(30 \mathrm{~W} / \mathrm{m}^{2}\right)$ and CERES $\left(29 \mathrm{~W} / \mathrm{m}^{2}\right)$ observations. The precipitation rate is $2.87 \mathrm{~mm} /$ day, slightly higher than observations.

Figure 1 shows the annual average zonal mean liquid water path over ocean, ice water path, cloud top in-cloud droplet number concentration and droplet effective radius for liquid clouds, cloud top in-cloud ice crystal number and effective radius for cirrus clouds (for cloud top temperatures less than $-35^{\circ} \mathrm{C}$ ), shortwave cloud forcing, and longwave cloud forcing. Cloud top droplet number concentrations have a strong north-south contrast with a larger number concentrations in the $\mathrm{NH}$, which is consistent with data derived from MODIS 
Table 4. Comparison of measured ice crystal number concentration ("Obs") during the INCA campaign (Gayet et al., 2004) over the SH (Punta Arenas, Chile, in March/April) and over the NH (Prestwick, Scotland, in September/October) with those simulated from the prognostic ice crystal equations in the model (unit: $\# / \mathrm{cm}^{3}$ ).

\begin{tabular}{llllllll}
\hline & HOM $^{\mathrm{a}}$ & HMHT_0.01IN & HMHT_0.1IN & HMHT_1IN $^{\mathrm{a}}$ & HMHT_1.25dT $^{\mathrm{a}}$ & HMHT_0.75dT $^{\mathrm{a}}$ & Obs $^{\mathrm{a}}$ \\
\hline Chile, SH & $0.20(0.14-0.29)^{\mathrm{c}} 0.38^{\mathrm{b}}$ & $0.15(0.13-0.22)^{\mathrm{c}}$ & $0.13(0.11-0.18)^{\mathrm{c}}$ & $0.18(0.14-0.26)^{\mathrm{c}}$ & $0.17(0.14-0.24)^{\mathrm{c}}$ & $0.15(0.13-0.18)^{\mathrm{c}}$ & $1.45(0.58-3.01)^{\mathrm{c}}$ \\
Scotland, NH & $0.20(0.14-0.29)^{\mathrm{c}} 0.41^{\mathrm{b}}$ & $0.13(0.11-0.17)^{\mathrm{c}}$ & $0.13(0.11-0.18)^{\mathrm{c}}$ & $0.24(0.15-0.50)^{\mathrm{c}}$ & $0.15(0.13-0.17)^{\mathrm{c}}$ & $0.15(0.13-0.17)^{\mathrm{c}}$ & $2.23(0.84-4.74)^{\mathrm{c}}$ \\
\hline
\end{tabular}

${ }^{a}$ Median values from the observations are shown. Model results are sampled every six hours over $60^{\circ}-50^{\circ} \mathrm{S}, 70^{\circ}-85^{\circ} \mathrm{W}$, from $\mathrm{March}$ to $\mathrm{May}$ in $\mathrm{Chile}$, and over $50^{\circ}-60^{\circ} \mathrm{N}$, $10^{\circ} \mathrm{W}-5^{\circ} \mathrm{E}$, from September to November in Scotland. Model results are restricted to pressure levels from $200 \mathrm{hpa}$ to $300 \mathrm{hPa}$, and to temperatures from $-35^{\circ} \mathrm{C}$ to $-60^{\circ} \mathrm{C}$.

$\mathrm{b}$ The second set of numbers of each location in the HOM case are median ice crystal number concentrations immediately after the initial homogeneous freezing.

c Numbers in parentheses represent the 25 to 75 percentile.
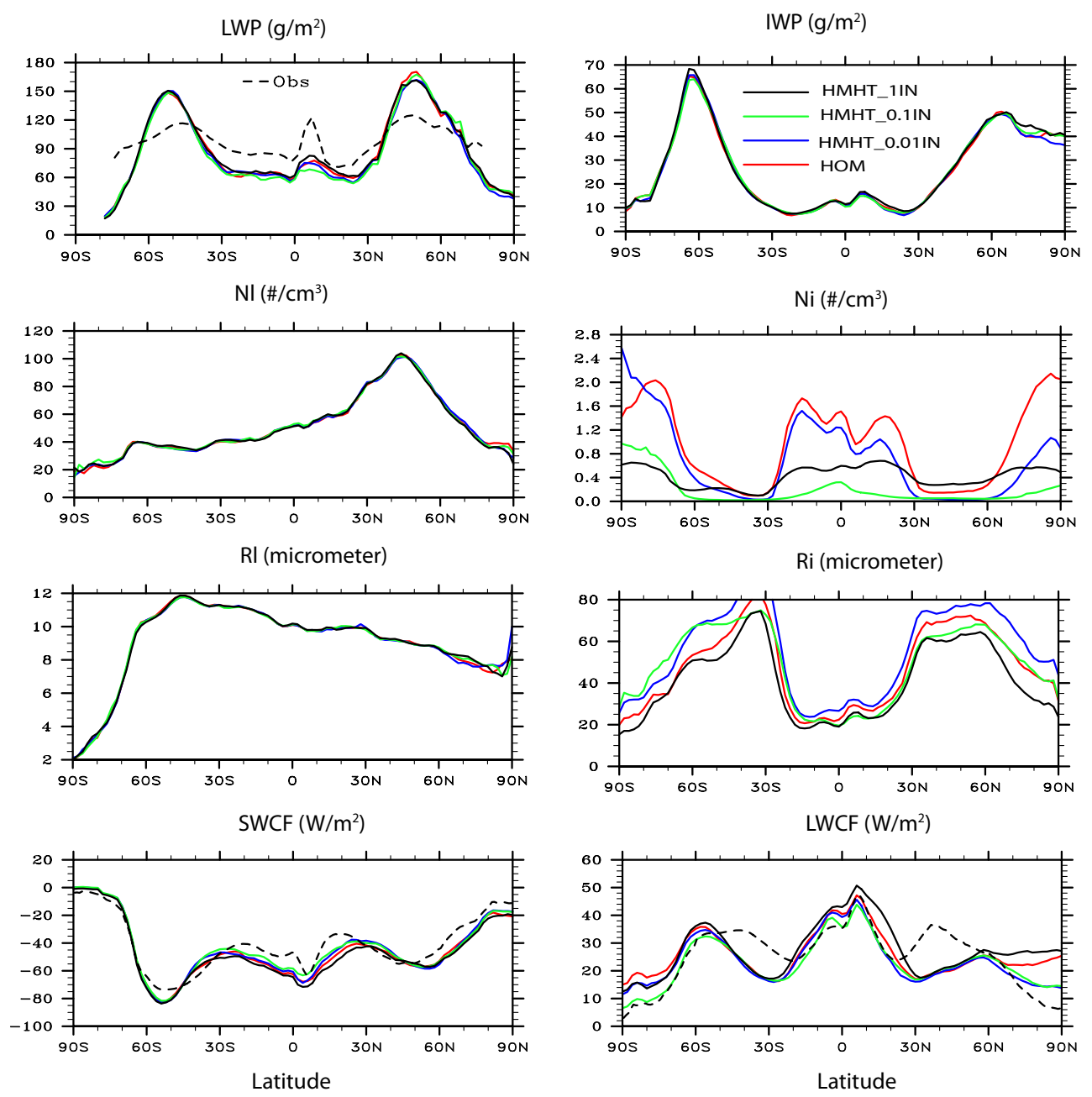

Fig. 1. Annual average zonal mean liquid water path over ocean (LWP, $\left.g / \mathrm{m}^{2}\right)$, ice water path (IWP, $\left.\mathrm{g} / \mathrm{m}^{2}\right)$, cloud top in-cloud liquid droplet number concentration $\left(N_{l}, \# / \mathrm{cm}^{3}\right)$, cloud top liquid droplet effective radius $\left(R_{l}, \mu \mathrm{m}\right)$, cirrus cloud top in-cloud ice crystal number $\left(N_{i}, \# / \mathrm{cm}^{3}\right)$, and cirrus cloud top ice crystal radius $\left(R_{i}, \mu \mathrm{m}\right)$, shortwave cloud forcing $\left(\mathrm{SWCF}, \mathrm{W} / \mathrm{m}^{2}\right)$, and longwave cloud forcing $\left(\mathrm{LWCF}, \mathrm{W} / \mathrm{m}^{2}\right)$ for four cases: HOM, HMTH_0.01IN, HMHT_0.1IN, HMHT_1IN. Observations for liquid water path, shortwave and longwave cloud forcing are included as the dashed black line. Shortwave and longwave cloud forcing are from CERES data for the years 2000-2005 (http://science. larc.nasa.gov/ceres), and liquid water path over ocean is from SSM/I data for the years 1987-2000 (http://www.ncdc.noaa.gov/oa/satellite/ ssmi/ssmiproducts.html). 

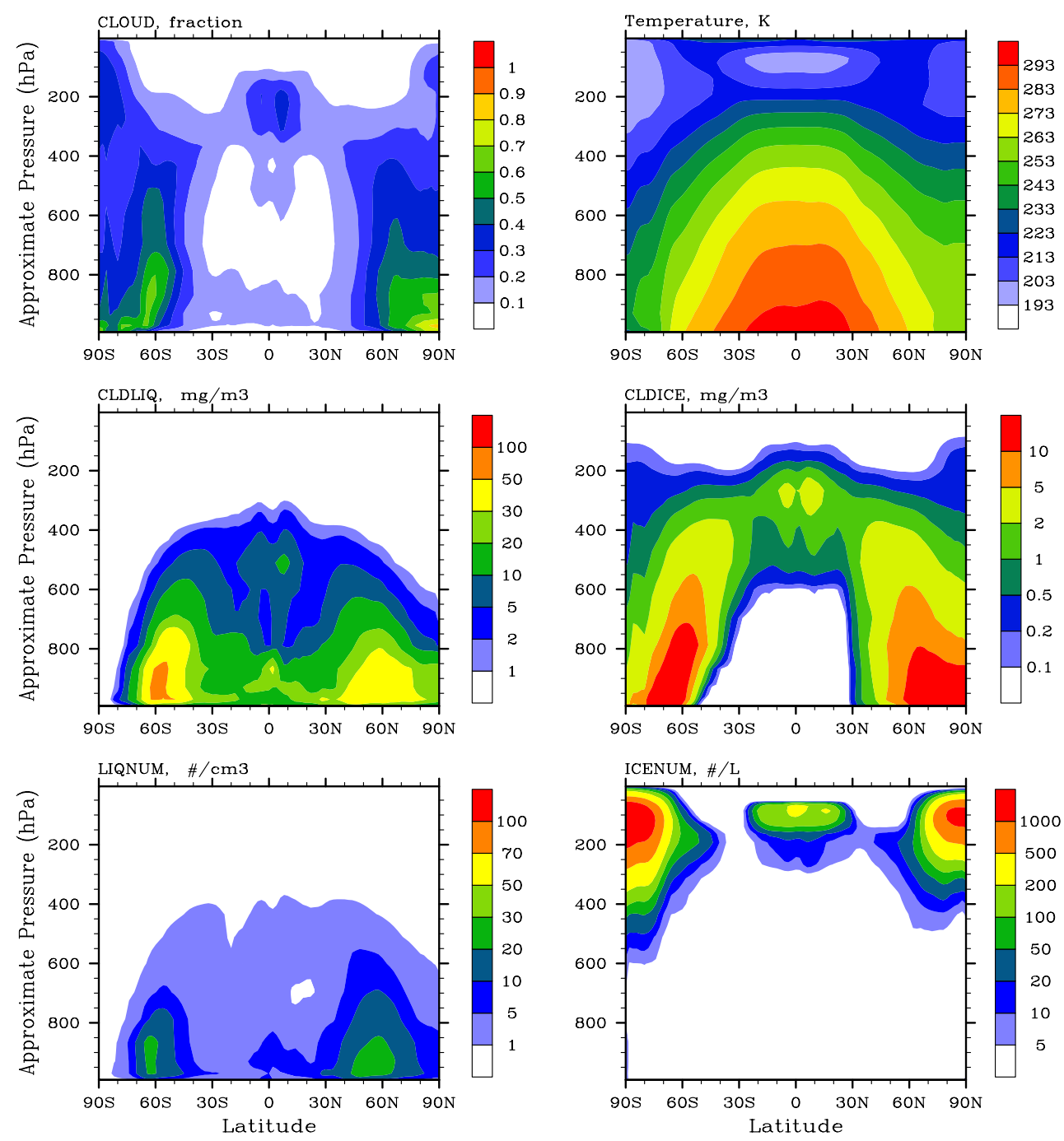

Fig. 2. Annual average zonal mean cloud fraction (CLOUD), temperature (K), grid-mean cloud liquid water content (CLDLIQ, $\left.\mathrm{mg} / \mathrm{m}^{3}\right)$,

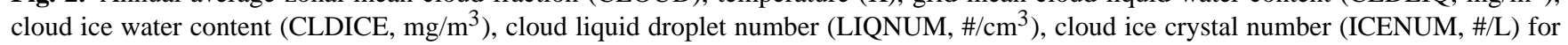
the HOM case.

observations (Quaas et al., 2006), and is mainly caused by anthropogenic aerosols in the model. Correspondingly, cloud top droplet effective radius has a larger value in the SH than in the $\mathrm{NH}$, which is consistent with the AVHRR observations (Han et al., 1994). Liquid water path has larger values in the middle latitude storm tracks over both hemispheres, which is consistent with SSM/I data (Ferraro et al., 1996). The ice water path has two peak values in the middle latitudes of both hemispheres, which is consistent with ISCCP observations (Storelvmo et al., 2008). For cirrus clouds, cloud top ice crystal number concentration is large over the tropics and the two polar regions. The ice crystal effective radius has two peaks in the middle latitudes of both hemispheres, with minima in the tropics and the two polar regions. The minima in the tropics is not consistent with MODIS data, which have a larger ice crystal radius in the tropics than those in the middle latitudes. Shortwave cloud forcing and longwave cloud forcing have similar latitudinal variations to those of the CERES observations, while the model underestimates longwave cloud forcing in the $\mathrm{SH}$ from $25^{\circ} \mathrm{S}-45^{\circ} \mathrm{S}$ and in the $\mathrm{NH}$ from $30^{\circ} \mathrm{N}-50^{\circ} \mathrm{N}$.

Figure 2 shows annual average zonal mean latitudepressure cross sections for grid-averaged droplet number concentration, liquid water content, ice crystal number concentration, and ice water content. Liquid water content shows two peaks in the storm tracks of both hemispheres, which extend into the middle troposphere. Liquid droplet number concentrations show a similar pattern: two peaks in the middle latitudes in both hemispheres, but the influence of anthropogenic aerosols is also evident: there is a stronger peak in the NH than in the SH. For ice clouds, large ice crystal number concentrations are found over the upper 

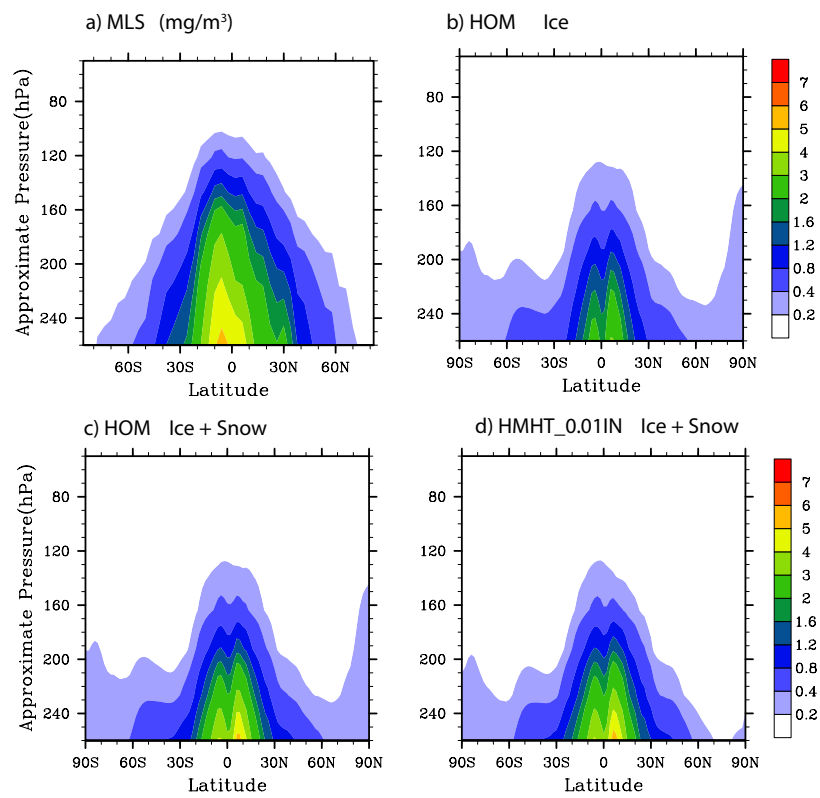

Fig. 3. Annual average zonal mean (a) grid-averaged ice water content that measured by the Aura MLS instrument, (b) gridaveraged ice water content in HOM, (c) grid-averaged ice water content + snow water content in HOM and (d) grid-averaged ice water content + snow water content in HMHT_0.01IN $\left(\mathrm{mg} / \mathrm{m}^{3}\right)$.

troposphere from tropical regions and at both poles. The simulated grid mean ice crystal number concentrations are comparable to results from Lohmann et al. (2007), except that they simulated higher ice crystal number concentrations in mixed-phase clouds, as mentioned above. Large ice water content can be found in the lower troposphere over high latitudes in both hemispheres and in the upper troposphere in the tropics.

Ice water content (IWC) in the upper troposphere is compared with that from the Microwave Limb Sounder (MLS) onboard the Aura Satellite (Wu et al., 2006) in Fig. 3. The MLS ice water content data have a vertical resolution of $\sim 3.5 \mathrm{~km}$ and a horizontal resolution of $\sim 160 \mathrm{~km}$ for a single MLS measurement along an orbital track (Wu et al., 2006; 2009). The data used here for comparison are monthly means from September 2004 to August 2005. In the model results, both ice water and the sum of ice water and snow water are shown since satellite measurements have difficulties to distinguish ice water from snow water (Waliser et al., 2009). Snow water is estimated from the diagnostic parameters of the production rate and evaporation rate of precipitation, following the comparison approach used in Gettleman et al. (2008). The model broadly captures the spatial and zonal distribution of ice water content in the upper troposphere, but the modeled ice water without snow underestimates the ice water content in tropical regions by a factor of 2 to 4 . Including snow water improves the comparison with the MLS data, though ice water is still underestimated
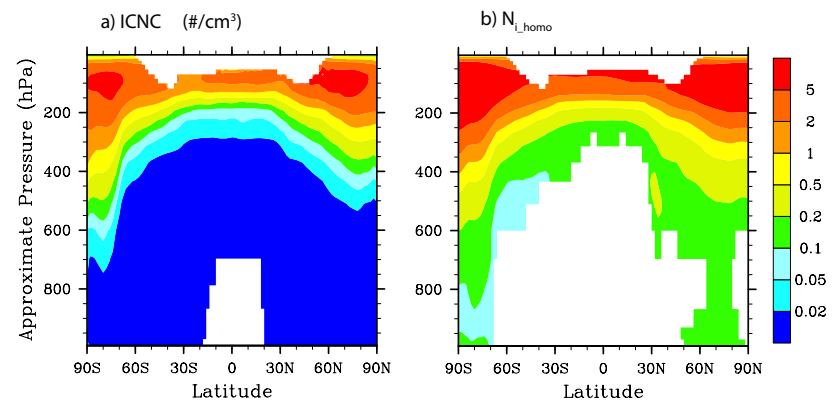

Fig. 4. Annual average zonal mean (a) in-cloud ice crystal number concentration $\left(\# / \mathrm{cm}^{3}\right)$ predicted by the prognostic ice crystal equation and (b) that calculated after the initial nucleation in the HOM case.

in tropical regions. The model ice water content is larger at the poles than in MLS data, a feature that is improved when heterogeneous IN are included in the model (see Sect. 4.1.2).

Figure 4 shows annual average zonal mean latitudepressure cross sections for the in-cloud ice crystal number concentration from the prognostic ice crystal equation and that simulated immediately after the initial ice nucleation. Ice crystal number concentration from the initial nucleation of ice ranges from 0.1 to $10 / \mathrm{cm}^{3}$, and increases with increasing altitude. The ice crystal number concentrations predicted from the prognostic ice crystal equation are lower by a factor of 2 to 5 compared to the initial concentrations predicted after ice nucleation, due to the impact of sublimation, gravitational settling, precipitation removal, and advection.

Table 4 compares the simulated ice crystal number concentration from the prognostic ice crystal equation in the HOM case with those measured during the INCA campaign (Gayet et al., 2004). Ice crystal number concentrations were measured in middle latitude cirrus clouds at temperatures ranging from $-33^{\circ} \mathrm{C}$ and $-60^{\circ} \mathrm{C}$ during the INCA campaign over Punta Arenas in the SH (Chile, in March/April) and over Prestwick in the NH (Scotland, in September/October). Most flight patterns during the campaign were designed to probe young cirrus clouds (Kärcher and Ström, 2003). The PMS FSSP-300 optical particle counter and the PMS 2D-C probe were used to measure particles with a size range of $3 \mu \mathrm{m}$ to $800 \mu \mathrm{m}$ in diameter. The measured ice crystal number concentrations in the $\mathrm{SH}$ and $\mathrm{NH}$ have a median of 1.4 and $2.2 / \mathrm{cm}^{3}$, respectively (Gayet et al., 2004). Simulated median ice crystal number concentrations from the prognostic ice crystal equation in the HOM case are $0.20 / \mathrm{cm}^{3}$ in the $\mathrm{SH}$ and $\mathrm{NH}$, while freshly nucleated ice crystal number concentrations are 0.38 and $0.41 / \mathrm{cm}^{3}$ in the $\mathrm{SH}$ and $\mathrm{NH}$, respectively. Both simulated ice crystal number concentrations and freshly nucleated ice crystal number concentration are significantly lower than the observed ice crystal number concentrations during the INCA campaign. The underestimation may partially come from 
a) HOM: ICNC

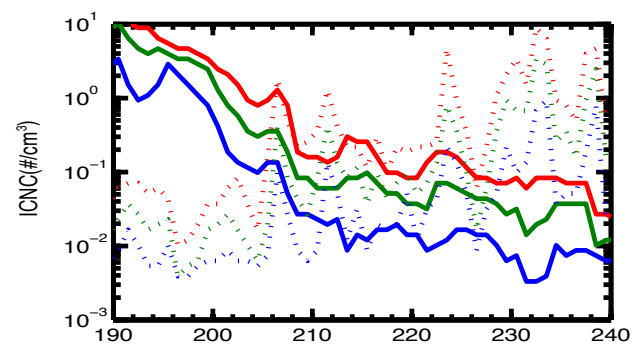

c) HMHT_0.01IN: ICNC

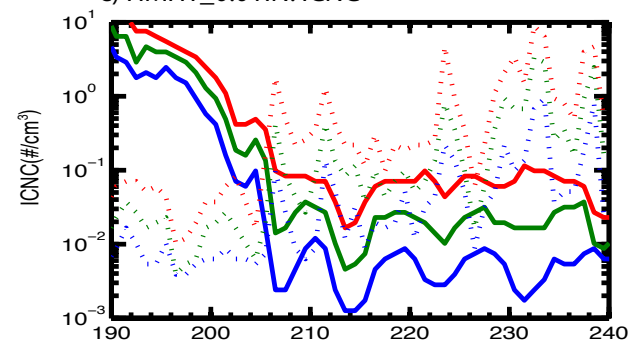

e) HMHT_0.1IN: ICNC

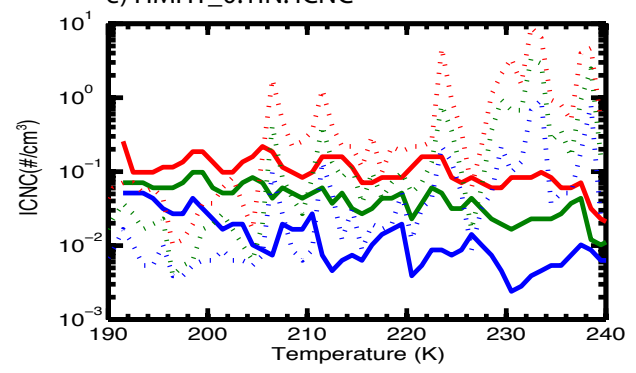

b) HOM: REI

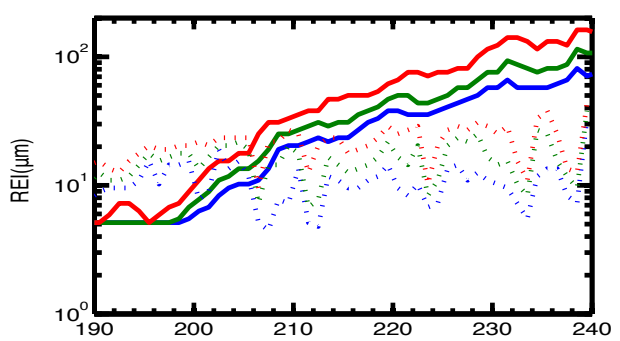

d) HMHT_0.01IN: REI

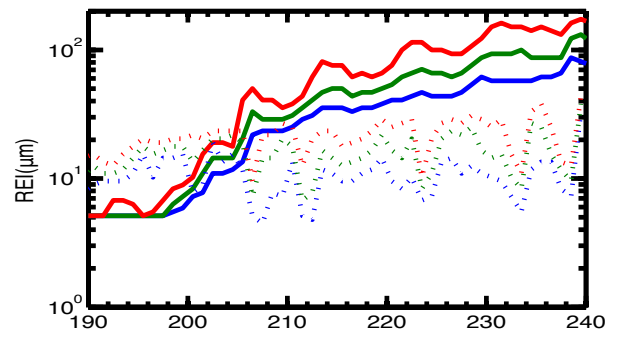

f) HMHT_0.1IN: REI

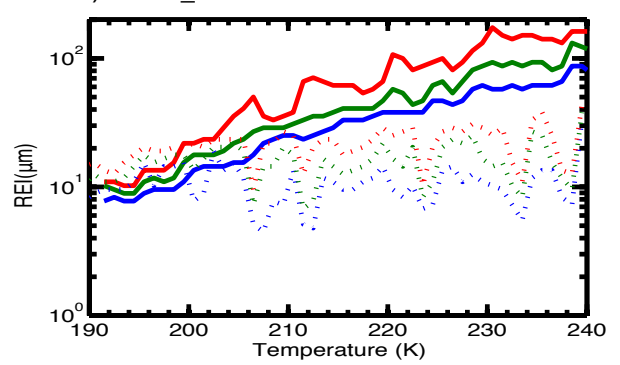

Fig. 5. In-cloud ice crystal number concentration $\left(\mathrm{ICNC}, \# / \mathrm{cm}^{3}\right)$ and ice crystal effective radius (REI, $\left.\mu \mathrm{m}\right)$ versus temperature. Model results are sampled every six hours over six flight regions (Kiruna, Sweden in January and February; Hohn, Germany in November and December; Forli, Italy in Octorber; Mahe, Seychelles, in February and March; Darwin, Australia, in November; Aracabuta, Brazil in January and February) where the observation reported in Krämer et al. (2009) were collected (see Table 3 in Krämer et al. (2009) for the flight information). The 50 percentile (green line), $25 \%$ percentile (blue line), and $75 \%$ percentile (red line) are shown for each $1 \mathrm{~K}$ temperature bins. Model results (solid lines) are from the HOM case (a, b), HMHT_0.01IN case (c, d), and HMHT_0.1IN case (e, f). Observations (dotted lines) are from data used in Fig. 9 in Kramer et al. (2009).

the altitude-dependent Gary mesoscale temperature formula. The Gary formula gives a mesoscale temperature perturbation of less than $0.5 \mathrm{~K}$ at $200-300 \mathrm{hPa}$ in the middle latitudes of both hemispheres, which is smaller than that observed in the INCA campaign (around $1 \mathrm{~K}$, see KB08).

Figure 5 compares in-cloud ice crystal number concentration (ICNC) and ice crystal effective radius (REI) versus temperature in the HOM case with those observed in Krämer et al. (2009) who examined aircraft in-situ observations of ice crystal number concentrations from 28 flights in tropical, midlatitude, and Arctic field experiments in the temperature range of 183-250 K. FSSP 100 and 300 instruments were used to measure the ice crystal number concentration. The FSSP 100 and FSSP 300 samples particles in the size range from $1.5-15$ and 2-20 $\mu$ m diameter, respectively. As shown in Kramer et al. (2009), at least $80 \%$, but typically $90 \%$ of total ice crystal number concentrations are within the FSSP size range. Model results were sampled every six hours over the six regions reported in Krämer et al. (2009) (i.e. Kiruna, Sweden in January and February; Hohn, Germany in November and December; Forli, Italy in October; Mahe, Seychelles, in February and March; Darwin, Australia, in November; Aracabuta, Brazil in January and February) (see Table 3 in Krämer et al. (2009) for the flight information). The median, $25 \%$ percentile, and $75 \%$ percentile are shown for each $1 \mathrm{~K}$ temperature bin. The measured ice crystal number concentrations decrease with decreasing temperature, with a median value $\sim 1.0 / \mathrm{cm}^{3}$ at $230 \mathrm{~K}$ and $\sim 0.02 / \mathrm{cm}^{3}$ at $200 \mathrm{~K}$.

In contrast, simulated ice crystal number concentrations in the HOM case strongly increase with decreasing temperature (the median ice crystal number concentration is $0.03 / \mathrm{cm}^{3}$ at $230 \mathrm{~K}$ and $2.0 / \mathrm{cm}^{3}$ at $200 \mathrm{~K}$ ). The HOM case 

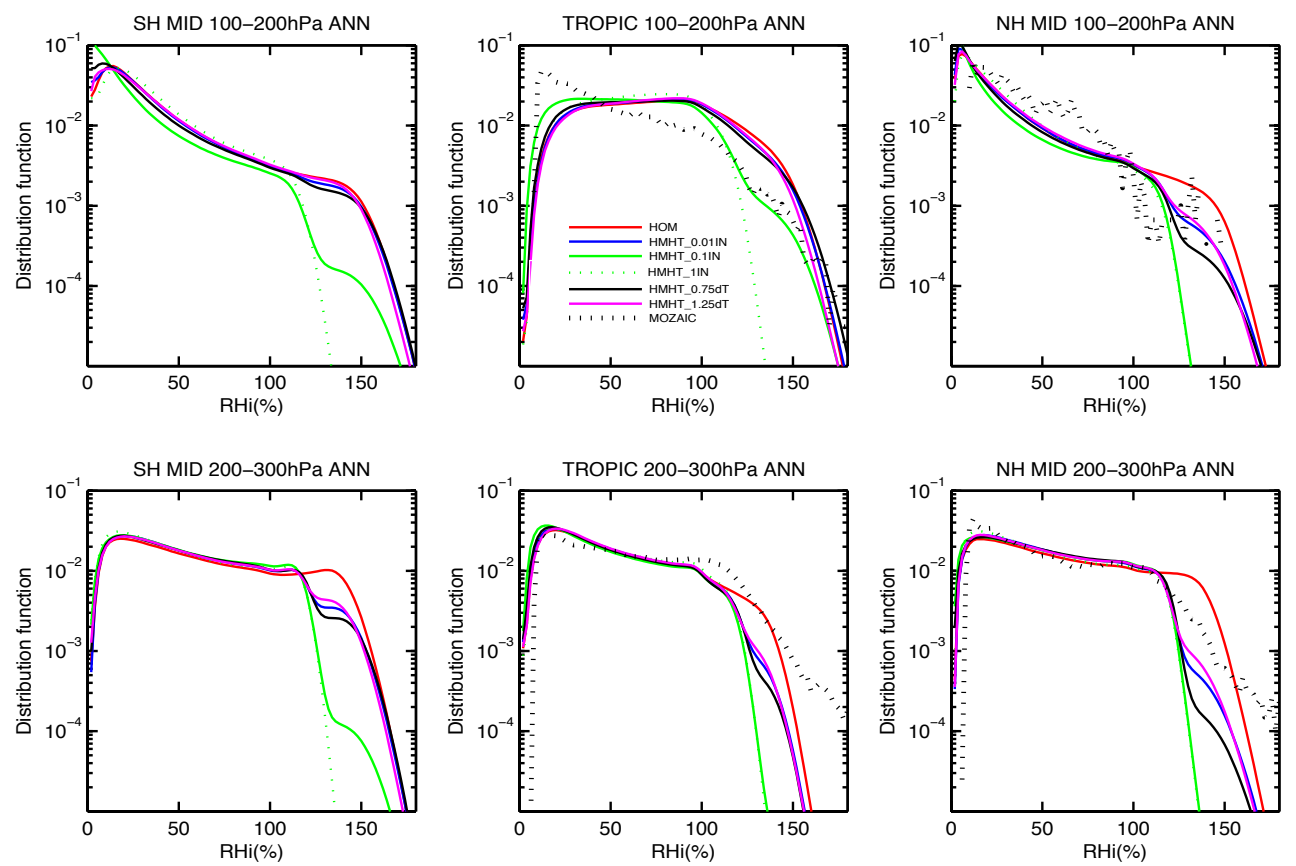

Fig. 6. Frequency of occurrence of $\mathrm{RH} i$ in the $\mathrm{SH}$ middle latitudes $\left(60^{\circ} \mathrm{S}-30^{\circ} \mathrm{S}\right)$ (SH MID, left panel), in the tropics $\left(30^{\circ} \mathrm{S}-30^{\circ} \mathrm{N}\right)(\mathrm{TROPIC}$, middle panel), and the $\mathrm{NH}$ middle latitudes $\left(30^{\circ} \mathrm{N}-60^{\circ} \mathrm{N}\right)(\mathrm{NH} \mathrm{MID}$, right panel) at 100-200 $\mathrm{hPa}$ (upper panel) and at 200-300 hPa (lower panel) from all simulations listed in Table 1. Observations from MOZAIC data in the tropics and in the NH middle latitudes are also shown.

overestimates ice crystal number concentrations by 1 or 2 orders of magnitude at low temperatures $(<205 \mathrm{~K})$, and underestimates ice crystal number concentrations at warm temperatures $(>205 \mathrm{~K})$. The underestimation at warm temperatures may be due to the small mesoscale temperature perturbation predicted by the Gary formula at lower altitudes, as described for the comparison with the INCA measurements. The overestimation at low temperatures is unlikely to be caused by the Gary temperature perturbation since one expects increases in temperature perturbations with altitude, as in the Gary model. The overestimation at low temperatures was also seen in a parcel model study by Jensen et al. (2010) who suggested that heterogeneous freezing could be the primary freezing mechanism in the tropical tropopause layer (at low temperatures). As shown later in Sect. 4.1.2, the inclusion of heterogeneous IN does improve the comparison with the observations. The simulated ice crystal radius increases with increasing temperature somewhat faster than that of the observations.

Figure 6 shows the simulated PDF of RHi outside of cirrus clouds within two layers $(100-200 \mathrm{hPa}$, and $200-300 \mathrm{hPa})$ and in three regions (the $\mathrm{SH}$ middle latitudes: $60^{\circ} \mathrm{S}-30^{\circ} \mathrm{S}$; the tropics: $30^{\circ} \mathrm{S}-30^{\circ} \mathrm{N}$; and the $\mathrm{NH}$ middle latitudes: $30^{\circ} \mathrm{N}-60^{\circ} \mathrm{N}$ ). One year of model results are sampled every six hours. The PDF of the clear-sky $\mathrm{RH} i$ is calculated based on the clear-sky mean $\mathrm{RH} i$ and the prescribed temperature perturbations used in the model (Sect. 2.2, Eq. A2) weighted by the clear sky fraction (1-a). Also shown in Fig. 6 is the PDF of RHi from the Measurement of Ozone and Water Vapor by Airbus In-service Aircraft (MOZAIC) campaign (Gierens et al., 1999) for the NH middle latitudes and the tropics. MOZAIC data sampled both clear sky and cloudy sky conditions. We only compared the RH $i$ in clear sky conditions because the model assumes a uniform distribution for the in-cloud specific humidity and the large time step used in the GCM makes the saturation ratio under cloudy sky conditions very close to 1 . In the clear sky, the $\mathrm{RH} i$ are sampled across the whole PDF spectrum regardless of whether the value of RH $i$ exceeds the heterogeneous freezing or homogeneous freezing threshold. Thus, the RH $i$ in clear skies is overestimated to some extent.

The homogeneous freezing-only case (HOM) captures the shape of the PDF of RH $i$ from MOZAIC data to a reasonable degree. $\mathrm{RH} i$ in the range from $20-100 \%$ occurs with large frequency, and the frequency has an almost exponential decay from $\mathrm{RH} i=100 \%$ to around $\mathrm{RH} i=150 \%$, a feature that is consistent with the MOZAIC data and is believed to be mainly caused by temperature variations (Kärcher and Haag, 2004). Beyond $150 \%$, the HOM case simulates a faster decay of RH $i$ than that in the MOZAIC data. This fast decay is caused by the homogeneous ice freezing threshold $\mathrm{RH} i$ near $150 \%$.

Figure 7 shows the geographical distribution of the frequency of occurrence of ice supersaturation in clear sky regions in the HOM case and from the Microwave Limb Sounder (MLS) satellite data (Spichtinger et al., 2003) at 

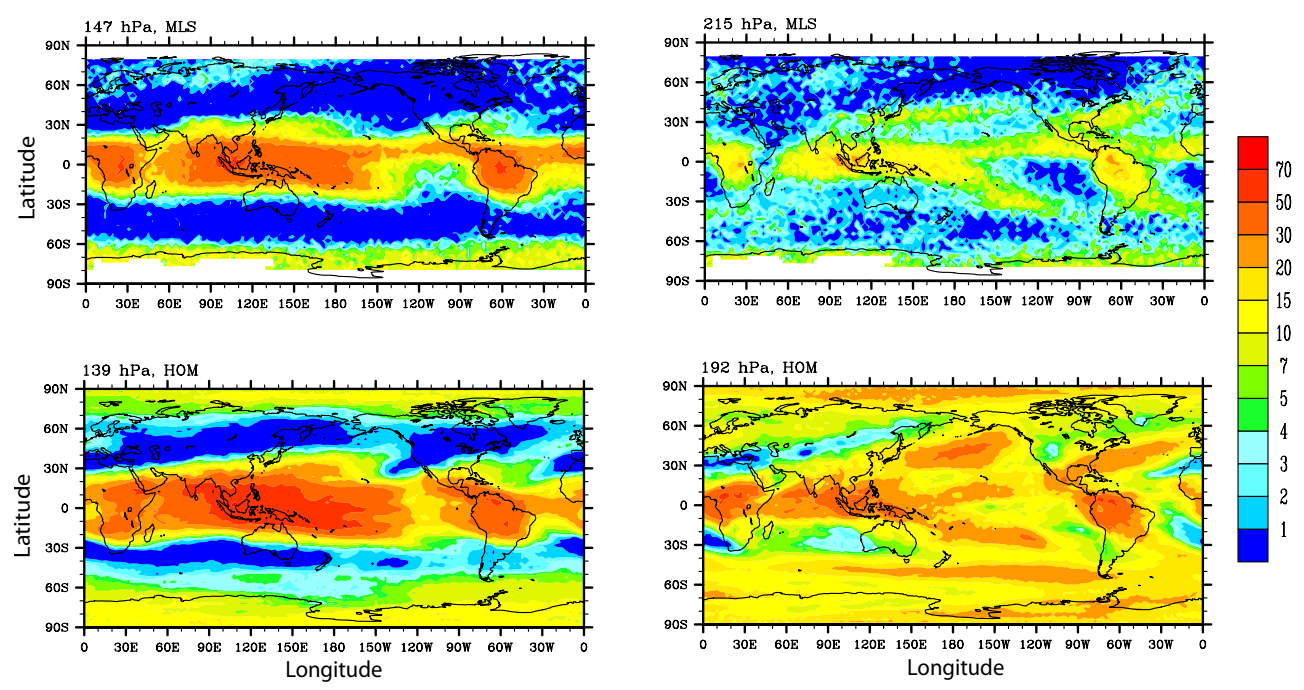

Fig. 7. Annual-average frequency of occurrence of ice supersaturation from MLS data (upper panel) for the HOM case (lower panel) at $147 \mathrm{hPa}(139 \mathrm{hPa}$ for the model) (left panel) and $215 \mathrm{hPa}(192 \mathrm{hPa}$ for the model) (lower panel).

pressure levels $147 \mathrm{hPa}(139 \mathrm{hPa}$ is shown for the model) and $215 \mathrm{hPa}(192 \mathrm{hPa}$ is shown for the model). The frequency of occurrence of ice supersaturation for a given grid point is calculated as the number of samples with $\mathrm{RH} i>100 \%$ divided by the total number of samples for a given period (one year in the model, September 1991 to June 1997 for the MLS data), weighted by the clear sky fraction (1-a). In contrast to the comparison with the MOZAIC data, the mean clear-sky RH $i$ instead of the subgrid-scale RH $i$ in the model is used to calculate the ice supersaturation frequency because of the large field view of the MLS measurement (about $100 \times 200 \mathrm{~km}^{2}$ perpendicular and parallel to the line of sight and $3 \mathrm{~km}$ vertically).

At the $147 \mathrm{hPa}$ level, the observed ice supersaturation occurs most frequently in the tropics between $20^{\circ} \mathrm{S}$ and $20^{\circ} \mathrm{N}$ and over Antarctica. Compared with the MLS data, the model with only homogeneous freezing (HOM) reproduces the observations well in terms of the spatial distribution, but gives a higher ice supersaturation frequency than does the MLS data. At the $215 \mathrm{hPa}$ level, the observed ice supersaturation occurs most frequently in the same regions as at the $149 \mathrm{hPa}$ level, although the high frequency ice supersaturation regions also extend toward high latitudes at $215 \mathrm{hPa}$, mainly over the storm track regions in both hemispheres. The model produces a similar spatial distribution as that in the MLS observations but with an even larger overestimation than that at $147 \mathrm{hPa}$, and the ice supersaturation regions extend even more towards high latitudes in the model. For example, the model simulates a high frequency of ice supersaturation occurrence in the SH storm track (around $45^{\circ} \mathrm{S}$ ), which is not present in the MLS observations. As pointed out by Spichtinger et al. (2003), there are considerable data gaps in the middle latitudes of the summer hemispheres in the
MLS data. This may prevent us from drawing further conclusions about whether the simulated ice supersaturation regions over the storm tracks at the $215 \mathrm{hPa}$ level is reasonable or not. To summarize the model performance regionally, averaged supersaturation frequencies in five regions (global, Northern Hemisphere, tropics, Southern Hemisphere, and Antarctic) in both the MLS data and the model are shown in Fig. 8. This confirms that geographical variations in supersaturation frequency are broadly captured, but with a significant overestimation, especially at $215 \mathrm{hPa}$, a feature that is improved when heterogeneous IN are included (Sect. 4.1).

\section{Effects of heterogeneous IN and mesoscale temperature perturbations}

\subsection{Effects of heterogeneous IN}

The effects of heterogeneous IN on cirrus cloud properties are studied using three sensitivity tests: HMHT_0.01IN, HMHT_0.1IN, and HMHT_1IN, in which IN concentrations are assumed to be $1 \%, 10 \%$, and $100 \%$ of the total number concentration of BC and dust particles, respectively, as described in Table 1 . The annual average zonal mean distributions of dust and $\mathrm{BC}$ number concentrations are shown in Fig. 9. BC particles have a high concentration in the $\mathrm{NH}$ upper troposphere $(100 \mathrm{hPa}$ to $400 \mathrm{hPa})$ with a range of $1-$ $10 / \mathrm{cm}^{3}$, caused by the larger anthropogenic emissions in the $\mathrm{NH}$. The number concentrations of BC particles in the upper troposphere decrease with latitude from north to south. In the upper troposphere of the $\mathrm{SH}$, the concentrations range from 0.3 to $1 / \mathrm{cm}^{3}$. Dust particles are much lower in number concentration and there is a stronger gradient with altitude from the surface to the upper troposphere than for BC 
(a) $149 \mathrm{hPa}$

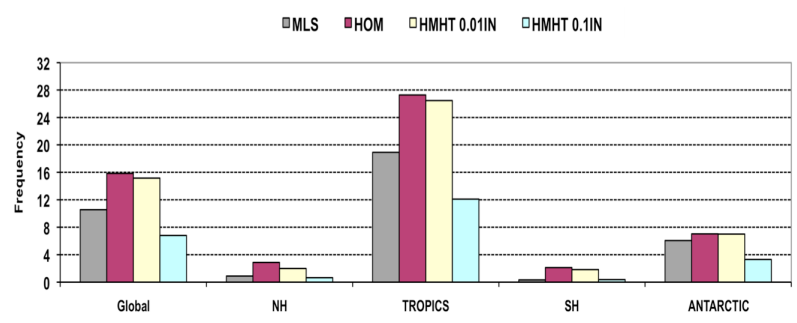

(b) $215 \mathrm{hPa}$

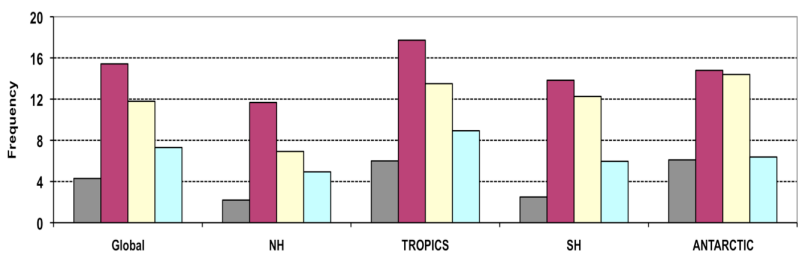

Fig. 8. Regionally-averaged frequency of occurrence of ice supersaturation from MLS data and from three simulations: HOM, HMHT_0.01IN, and HMHT_0.1IN, (a) at $149 \mathrm{hPa}(139 \mathrm{hPa}$ for the model) and at (b) $215 \mathrm{hPa}$ (192 hPa for the model) over five regions: Global $\left(80^{\circ} \mathrm{S}-80^{\circ} \mathrm{N}\right)$, $\mathrm{NH}$ (Northern Hemisphere, $30^{\circ} \mathrm{N}-80^{\circ} \mathrm{N}$ ), TROPICS $\left(30^{\circ} \mathrm{N}-30^{\circ} \mathrm{S}\right), \mathrm{SH}$ (Southern Hemisphere, $55^{\circ} \mathrm{S}-30^{\circ} \mathrm{S}$ ), and Antarctic $\left(80^{\circ} \mathrm{S}-55^{\circ} \mathrm{S}\right)$.
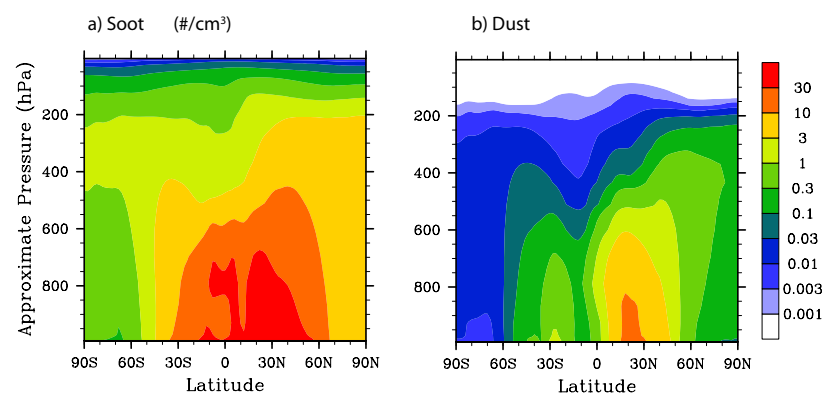

Fig. 9. Annual average zonal mean (a) soot and (b) dust number concentration $\left(\# / \mathrm{cm}^{3}\right)$.

particles because of their larger sizes and the lack of a source in the upper troposphere. The number concentrations of dust particles range from 0.001 to $1 / \mathrm{cm}^{3}$ in the $\mathrm{NH}$ upper troposphere, and range from 0.001 to $0.03 / \mathrm{cm}^{3}$ in the $\mathrm{SH}$ upper troposphere.

\subsubsection{Effects on humidity fields}

Figure 6 shows the effect of heterogeneous IN on the frequency of occurrence of RHi. At 100-200 hPa, heterogeneous freezing has little effect in the tropics and in the $\mathrm{SH}$ when only $1 \%$ of soot and dust particles act as IN as in the HMHT_0.01IN case, because the IN concentration is too low in these regions to affect supersaturation levels. However, in the NH middle latitudes, the IN concentration is large enough to affect supersaturation levels and decreases the frequency of occurrence of very high supersaturations due to their lower threshold $\mathrm{RH} i$ which is assumed to be between 120-130\% in the parameterization of Liu and Penner (2005). At 200$300 \mathrm{hPa}$, the effects of heterogeneous IN are significant at all latitudes, and their effects are stronger in the NH than in the $\mathrm{SH}$. The hemispheric contrast in the PDF of the RH $i$ in this case is consistent with that observed in the INCA field campaign (Haag et al., 2003). Homogeneous freezing occurs less frequently when the IN concentration increases by a factor of 10 in the HMHT_0.1IN case. In the tropics at $200-300 \mathrm{hPa}$, and in the middle latitudes of the $\mathrm{NH}$ at both $100-200 \mathrm{hPa}$ and $200-300 \mathrm{hPa}$, heterogeneous freezing shuts off homogeneous freezing, as evidenced by the very low frequency of $\mathrm{RH} i$ values higher than $150 \%$. In the tropics at $100-200 \mathrm{hPa}$, and in the middle latitudes of the $\mathrm{SH}$, homogeneous freezing still occurs but with a much lower frequency than that in the HMHT_0.01IN case. Homogeneous freezing is shut down almost everywhere in the HMHT_1IN case when $100 \%$ of the $\mathrm{BC}$ and dust particles act as heterogeneous IN.

The effects of heterogeneous IN can also be seen in the simulated regionally averaged frequency of occurrence of ice supersaturation at $139 \mathrm{hPa}$ and $192 \mathrm{hPa}$ in Fig. 8 . When $1 \%$ of dust and BC particles act as heterogeneous IN (HMHT_0.01IN), the simulated supersaturation frequencies decrease, with larger decreases over the NH than the SH, and larger decreases at $215 \mathrm{hPa}$ than at $147 \mathrm{hPa}$ because of the higher IN concentrations. For example, at $215 \mathrm{hPa}$, the simulated supersaturation frequencies in the HOM case and the HMHT_0.01IN case are almost the same at SH middle latitudes, but decrease from $13 \%$ in the HOM case to $6 \%$ in the HMHT_0.01IN case in the NH middle latitudes. When heterogeneous IN concentrations increase by a factor of 10 in the HMHT_0.1IN case, supersaturation frequencies in all regions and at both $147 \mathrm{hPa}$ and $215 \mathrm{hPa}$ decrease significantly. These model results show that ice microphysics is important for simulating supersaturation frequencies in the upper troposphere. Including heterogeneous IN decreases simulated supersaturation frequencies in the model, and improves the comparison with the frequencies of supersaturation from the MLS data at $215 \mathrm{hPa}$. But this conclusion has to be treated cautiously given the uncertainties associated with the MLS retrievals. Read et al. (2001) showed that the global-averaged accuracy of RH $i$ from the MLS retrievals are $22 \%$ and $23 \%$ at $147 \mathrm{hPa}$ and $215 \mathrm{hPa}$, respectively.

\subsubsection{Effects on cloud fields}

Since heterogeneous freezing requires lower $\mathrm{RH} i$, adding heterogeneous IN leads to cloud fraction increases. Total cloud fraction increases from $66.1 \%$ in the HOM case to $68.2 \%$ in the HMHT_1IN case (Table 2).

Heterogeneous IN can significantly affect the simulated ice crystal number concentrations, as shown in Fig. 5, Fig. 10, and Tables 2 and 4. Figure 10 shows the annual 

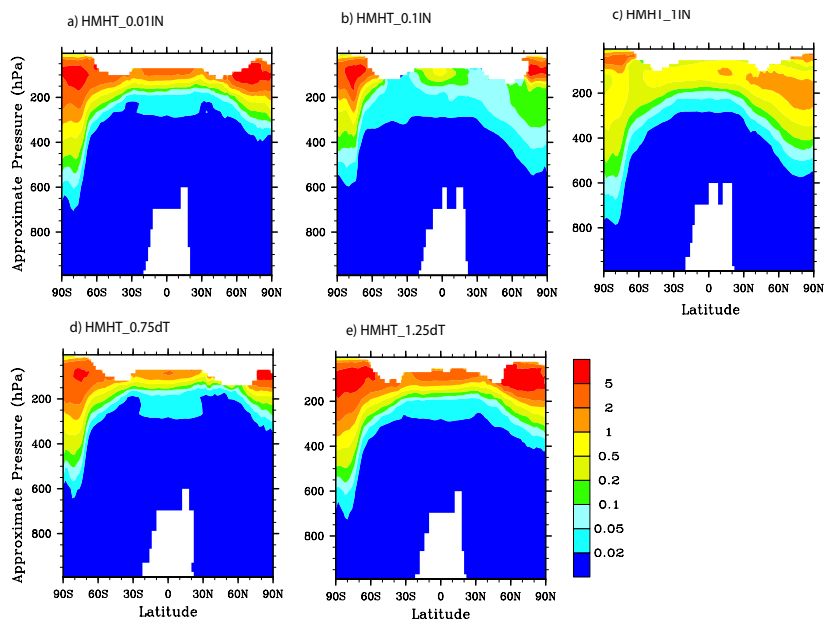

Fig. 10. Annual average zonal mean ice crystal number concentration $\left(\# / \mathrm{cm}^{3}\right)$ in all five cases that allow the competition between homogeneous freezing and heterogeneous freezing. All cases are described in Table 1.

average latitude-pressure cross sections of in-cloud ice crystal number concentration in all cases where the competition between homogeneous freezing and heterogeneous freezing is allowed. The results show that in an environment dominated by homogeneous freezing, the addition of heterogeneous IN decreases the ice crystal number concentration. In both the HOM case and the HMHT_0.01IN case homogeneous freezing dominates, as seen in the PDF of RH $i$ (Fig. 6). There is a $30 \%$ decrease in column-integrated ice crystal number concentration from the HOM case $\left(0.088 \times 10^{10} / \mathrm{m}^{2}\right)$ to the HMHT_0.01IN case $\left(0.062 \times 10^{10} / \mathrm{m}^{2}\right)$ and a $63 \%$ decrease from the HMHT_0.01IN case $\left(0.062 \times 10^{10} / \mathrm{m}^{2}\right)$ to the HMHT_0.1IN case $\left(0.023 \times 10^{10} / \mathrm{m}^{2}\right)$ (Table 2). On the other hand, when the environment is dominated by heterogeneous freezing, adding heterogeneous IN increases ice crystal number concentrations. There is a significant increase in ice crystal number concentration in the HMHT_1IN case compared with that in the HMHT_0.1IN case because heterogeneous freezing dominates in the HMHT_0.1IN case (Fig. 10c and Fig. 10b; Table 4). The column-integrated ice crystal number concentration is doubled from $0.023 \times 10^{10} / \mathrm{m}^{2}$ in HMHT_0.1IN to $0.050 \times 10^{10} / \mathrm{m}^{2}$ in HMHT_1IN (Table 2). Our results show that the background ice freezing mode determines the sign of the change in ice crystal number concentration from the addition of heterogeneous IN, which is consistent with previous studies (e.g., Hendricks et al., 2005; Penner et al., 2009).

If $1 \%$ of soot and dust particles act as heterogeneous IN, there is little effect on the simulated ice crystal number concentrations at low temperatures $(<205 \mathrm{~K})$ but decrease ice crystal number concentrations at warmer temperatures $(>205 \mathrm{~K})$ compared to the HOM case, which makes the comparison with observations somewhat less favorable
(Fig. 5c). When $10 \%$ of the $\mathrm{BC}$ and dust particles can act as heterogeneous IN (Fig. 5e), the simulated ice crystal number concentration are significantly improved at low temperatures $(<205 \mathrm{~K})$ in comparison with observations. This suggests that if heterogeneous IN were to increase significantly with decreasing temperatures (as in the Fletcher parameterization), the model may be able to reproduce the Krämer et al. (2009) observations.

Changes in the ice crystal number concentrations from the addition of heterogeneous IN affect ice crystal radii (see Fig. 1, Fig. 5, and Table 2). Larger ice crystal number concentrations lead to smaller ice crystal radii. The HMHT_0.01IN case has larger ice crystal radii than those in the HOM case because the HMHT_0.01IN case has lower ice crystal number concentrations (Fig. 1f). The HMHT_1IN case has the smallest ice crystal radii at the tops of cirrus clouds $(41.5 \mu \mathrm{m}$ in Table 2, and Fig. 1), although the cloud top ice crystal number concentration is smaller than that from the HOM case. This is due to differences in the vertical profile of ice crystal number concentrations between HMHT_1IN and HMHT_0.1IN. Although the HOM case has larger column-integrated ice crystal number concentrations than does HMHT_1IN, the ice crystal number concentrations in most regions where ice water content is large are smaller (see Fig. 2).

Since ice crystal radius determines the settling velocity of ice crystals, and since gravitational settling is a very important removal mechanism for cirrus clouds in the upper troposphere, changes in ice crystal radii lead to changes in cirrus cloud lifetimes and ice water content in the upper troposphere. One example is shown in Fig. 3. When ice crystal number concentrations decrease from the HOM case to the HMHT_0.01IN case, ice crystal radius increases, which increases the gravitational settling and decreases the excessive ice water simulated over the Arctic in HOM, thereby improving the comparison with MLS observations (compare Fig. 3c and Fig. 3b).

The changes in cirrus clouds (ice crystal number concentrations and cloud fraction) also affect liquid clouds (Table 2). Less ice crystal number concentration usually leads to smaller liquid water path and low level cloud fraction. For example, when ice crystal number concentration increases from the HMHT_0.1IN case to the HMHT_1IN case, the liquid water path increases by $7 \%$ from $75.4 \mathrm{~g} / \mathrm{m}^{2}$ to $81.0 \mathrm{~g} / \mathrm{m}^{2}$. Our results here are consistent with those of Wu (2002), Grabowski (2000), Jakob (2002) and Sanderson et al. (2008). $\mathrm{Wu}$ (2002) and Grabowski (2000) found that a model with low ice crystal fall velocities would produce a more cloudy and moist lower troposphere with less precipitation. The increasing low level clouds and decreasing precipitation in our simulations are associated with decreasing convective activity, as is evident from the decreased convective precipitation rate (Table 3). For example, when ice crystal number concentrations increase from HMHT_0.IN to HMHT_1IN, the convective precipitation rate decreases from $2.00 \mathrm{~mm} /$ day in 
HMHT_0.1IN to $1.86 \mathrm{~mm}$ /day in HMTH_1IN. This is consistent with the findings of Jakob (2002) who showed that a smaller settling velocity leads to less convective precipitation and more liquid clouds. Less convective activity is likely caused by the increased heating in the upper troposphere and decreased surface insolation caused by increased cirrus clouds.

\subsubsection{Effects on radiative fluxes}

Changes in both the longwave and shortwave cloud forcing closely follow changes in cirrus clouds (Tables 2 and 3). Larger ice crystal number concentrations usually lead to smaller ice crystal radii and more ice water content in the upper troposphere. More cirrus clouds also lead to a larger liquid water path in the lower atmosphere (Sect. 4.1.2). All these changes lead to a larger longwave cloud forcing (warming) and larger shortwave cloud forcing (cooling). The HMHT_0.1IN case simulates the smallest longwave cloud forcing $\left(26.22 \mathrm{~W} / \mathrm{m}^{2}\right)$ and the smallest shortwave cloud forcing $\left(50.65 \mathrm{~W} / \mathrm{m}^{2}\right)$ because it has the lowest ice crystal number concentration. The HMHT_1IN case simulates the largest longwave cloud forcing $\left(54.3 \mathrm{~W} / \mathrm{m}^{2}\right)$ and the largest shortwave cloud forcing $\left(29.6 \mathrm{~W} / \mathrm{m}^{2}\right)$ because of its larger ice crystal number concentration and larger cirrus cloud fraction.

The simulated net cloud forcing is less sensitive to changes in cirrus clouds. Although both longwave and shortwave cloud forcing are affected by changes in high level cirrus clouds and lower level liquid clouds, changes in high level cirrus clouds have a larger effect on longwave cloud forcing and changes in low level liquid clouds have a larger effect on shortwave cloud forcing (e.g., Chen et al., 2000). When column-integrated ice crystal number concentrations decrease by $30 \%$ from the HOM case to the HMHT_0.01IN case, the net cloud forcing changes from $-25.02 \mathrm{~W} / \mathrm{m}^{2}$ to $-25.12 \mathrm{~W} / \mathrm{m}^{2}$ so that a net cooling of $0.10 \mathrm{~W} / \mathrm{m}^{2}$ is simulated, which indicates that the cooling from the change in the longwave cloud forcing dominates. But when columnedintegrated ice crystal number concentration decreases further by $63 \%$ from the HMHT_0.01IN case to the HMHT_0.1IN case, a net warming of $0.20 \mathrm{~W} / \mathrm{m}^{2}$ is simulated, which indicates that the warming from the change in the shortwave cloud forcing dominates.

Although the net change in cloud forcing is relatively small, the change in the net radiative fluxes (FNT) at the TOA is large (Table 3 ), with a maximum change of $1.7 \mathrm{~W} / \mathrm{m}^{2}$ between the four cases discussed here. The large changes in the net radiative flux at the TOA mainly comes from the change in clear sky longwave radiation (FLNTC) due to changes in water vapor in the atmosphere, especially in the upper troposphere. Fewer ice crystals lead to larger ice crystal radii, which leads to shorter cloud lifetimes and therefore less water vapor in the upper troposphere. Also, less heating from fewer cirrus clouds cools the upper troposphere and leads to lower temperatures (Fig. 11a) and to less water vapor in both
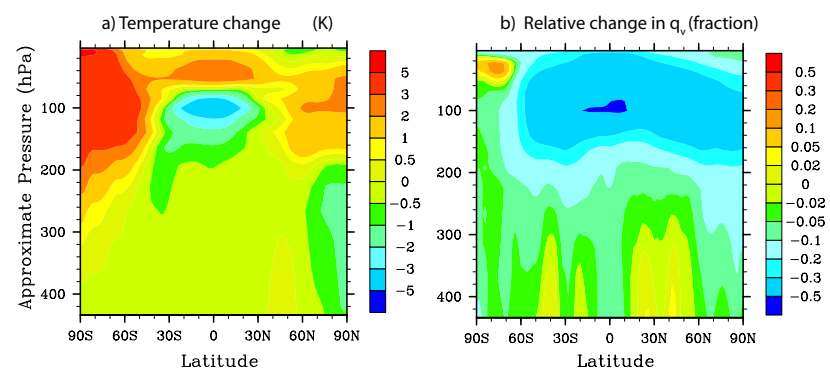

Fig. 11. Annual average zonal mean (a) temperature change (unit: $\mathrm{K}$ ) and (b) relative change in specific humidity (unit: fraction) from the HMHT_0.01IN case to the HMHT_0.1IN case.

the upper troposphere and stratosphere. The greenhouse effect of water vapor depends more on the relative change and less on the absolute change in water vapor (Raval and Ramanathan, 1989). Although the absolute change in the water vapor concentration in the upper troposphere is small between the different cases, the relative change can be large. For example, the integrated water vapor mass from $100 \mathrm{hPa}$ to $300 \mathrm{hPa}$ decreases by $10 \%$ from the HMHT_0.01IN case to the HMHT_0.1IN case (Fig. 11b), which contributes the most to the clear sky longwave cooling of $1.1 \mathrm{~W} / \mathrm{m}^{2}$. This overrides the warming in the net cloud forcing and leads to a net cooling of $0.94 \mathrm{~W} / \mathrm{m}^{2}$ at the TOA. Stratospheric water vapor also decreases significantly from the HMHT_0.01IN case to the HMHT_0.1IN case $(\sim 32 \%)$. This change in stratospheric water vapor has little effect on the clear sky TOA longwave radiative flux though it can have important effects on the clear sky radiative fluxes at the tropopause (Forster and Shine, 2002). A 1-D radiative transfer calculation with a typical tropical profile in winter showed that a $32 \%$ decrease in the stratospheric water vapor leads to a cooling of $0.65 \mathrm{~W} / \mathrm{m}^{2}$ at the tropopause.

\subsection{Effects of mesoscale temperature perturbations}

The effects of mesoscale temperature perturbations on simulated cirrus cloud properties were examined in two additional sensitivity tests (HMHT_0.75 $d T$ and HMHT_1.25dT). These two cases have the same IN concentration as in the HMHT_0.01IN case, but here the temperature perturbation decreases or increases by $25 \%$.

A $25 \%$ higher temperature perturbation in the HMHT_1.25 $d T$ case leads to a $25 \%$ higher cooling rate and vertical velocity since these latter two parameters are proportional to the temperature perturbation in our treatment (see Eq. (4) in Sect. 2.2). Higher cooling rates and vertical velocities limit the influence of heterogeneous IN, and lead to more homogeneous freezing, as seen in the simulated PDF of $\mathrm{RH} i$ in the $\mathrm{NH}$ middle latitudes at 100-200 hPa and in all latitude bands at 200-300 hPa (Fig. 6), and therefore lead to higher frequencies of $\mathrm{RH} i>150 \%$ than 
in the HMHT_0.01IN case. The opposite is true when the temperature perturbation is decreased by $25 \%$ in the HMHT_0.75dT case, which increases the influence of heterogeneous IN and leads to less homogeneous freezing (Fig. 6).

Simulated ice crystal number concentrations in HMHT_1.25 $d T$ are higher than in HMHT_0.01IN (compare Fig. 10a and e; Table 4). The competition between heterogeneous and homogeneous freezing coupled with the higher cooling rate leads to higher ice crystal numbers generated from homogeneous freezing. The columnintegrated ice crystal number concentration increases by $50 \%$ from $0.062 \times 10^{10} / \mathrm{m}^{2}$ in the HMHT_0.01IN case to $0.094 \times 10^{10} / \mathrm{m}^{2}$ in the HMHT_1.25 $d T$ case. The opposite is true for the HMHT_0.75 $d T$ case (compare Fig. 10a and d; Table 4). Homogeneous freezing occurs less often and produces fewer ice crystals because of lower vertical velocities so that the simulated column integrated ice crystal number concentration decreases by $33 \%$ from $0.062 \times 10^{10} / \mathrm{m}^{2}$ in the HMHT_0.01IN case to $0.041 \times 10^{10} / \mathrm{m}^{2}$ in the HMHT_0.75 $d T$ case.

The change in radiative fluxes depends on changes in ice crystal number concentration, as discussed in Sect. 4.1.3. A net warming of $0.43 \mathrm{~W} / \mathrm{m}^{2}$ in the cloud forcing is simulated in going from the HMHT_0.75 $d T$ case to the HMHT_1. $d T$ case, but this only contributes $40 \%$ to the increase in the simulated net TOA flux difference, which is $1.04 \mathrm{~W} / \mathrm{m}^{2}$. The remaining two thirds of the increase comes from the greenhouse effect of increased water vapor in the upper troposphere, which results from an increase in the ice crystal number concentration.

The magnitude of the changes in column-integrated ice crystal number concentration and radiative fluxes from different mesoscale temperature perturbations are comparable to those simulated from different heterogeneous IN concentrations (Sect. 4.1.3). For example, a $25 \%$ decrease in the temperature perturbation from the HMHT_0.01IN case to the HMHT_0.75dT case leads to a $33 \%$ decrease in columnintegrated ice crystal number concentration, a change in the net cloud forcing of $-0.16 \mathrm{~W} / \mathrm{m}^{2}$, and a change in the net TOA radiative flux of $-0.44 \mathrm{~W} / \mathrm{m}^{2}$, while a factor of 10 increase in the heterogeneous IN concentration from the HMHT_0.01IN case to the HMHT_0.1IN case leads to $63 \%$ decrease in column-integrated ice crystal number concentration, a net cloud forcing of $0.20 \mathrm{~W} / \mathrm{m}^{2}$, and the net TOA radiative fluxes of $-0.94 \mathrm{~W} / \mathrm{m}^{2}$. This points to the importance of mesoscale dynamics and subgrid scale variations in studying aerosol indirect effects on cirrus clouds (Haag and Kärcher, 2004; Penner et al., 2009).

\section{Summary and discussion}

We implemented an extended version of the statistical cirrus cloud scheme presented in KB08 in the NCAR CAM3 atmospheric circulation model component of the coupled IMPACT/CAM model. This cirrus cloud scheme has an assumed subgrid scale temperature variation in the clear sky and a subgrid scale variation of in-cloud water concentration in the cloudy sky, and has an improved treatment for the nucleation of ice crystals and cloud fraction. The KB08 scheme is extended to include a simplified representation of both homogeneous and heterogeneous freezing. The coupled model with the new cirrus cloud scheme is evaluated by comparing model results with observations, and the effects of heterogeneous IN and mesoscale temperature perturbations are examined using sensitivity tests.

The simulated model fields, including the liquid water path, ice water path, shortwave cloud forcing, longwave cloud forcing, cloud fraction, and precipitation are in reasonable agreement with observations. The new cirrus cloud scheme simulates significantly smaller high cloud fractions than in LIU07, where cloud fraction was diagnosed as in the standard CAM3 based on relative humidity. The simulated total cloud fraction ranges from $66.1 \%$ to $68.2 \%$ in all cases, and agrees well with observations. The simulated ice water content in the homogeneous freezing only case (HOM) broadly captures the spatial and zonal distribution of ice water content in the upper troposphere from the MLS data, but it underestimates ice water content in the tropics. The ice water content simulated in this case also spreads more toward the poles than in the MLS data, a feature that is improved when $1 \%$ of the $\mathrm{BC}$ and dust particles can act as heterogeneous IN.

When only homogeneous freezing is included in the model, the simulated PDF of RH $i$ outside of cirrus clouds has an exponential decay from $100 \% \mathrm{RH} i$ to $150 \% \mathrm{RH} i$ which agrees with MOZAIC in-situ data. Including heterogeneous IN changes the PDF of the $\mathrm{RH} i$ significantly. When $1 \%$ of the $\mathrm{BC}$ and dust particles act as heterogeneous IN with a low threshold freezing humidity of about $120-130 \% \mathrm{RH} i$, the frequency of occurrence of very high $\mathrm{RH} i$ at $100-200 \mathrm{hPa}$ in the $\mathrm{NH}$ middle latitudes and at $200-300 \mathrm{hPa}$ in all latitude bands decreases, but there is little effect in the SH and tropics at $100-200 \mathrm{hPa}$. The simulated hemispheric contrast in the PDF of the $\mathrm{RH} i$ in this case is consistent with that observed in the INCA field campaign (Haag et al., 2003). When heterogeneous IN concentrations are increased by a factor of 10, the frequency of high RH $i$ decreases significantly in both hemispheres. The simulated frequency of supersaturation at $139 \mathrm{hPa}$ and $192 \mathrm{hPa}$ agrees well with satellite observations in terms of its spatial distribution, but the model overestimates the magnitude of the supersaturation frequency when only homogeneous freezing is included, especially at $192 \mathrm{hPa}$. Including heterogeneous IN in the model decreases the supersaturation frequency and improves the 
comparison with satellite observations at $192 \mathrm{hPa}$.

The simulated ice crystal number concentrations in the middle latitudes of both hemispheres (Table 4) and at warmer temperatures (>205 K) (Fig. 5) are underestimated. This underestimation may point to problems with the Gary mesoscale temperature formula at low altitudes. The altitude dependence in the Gary formula predicts rather small temperature perturbations in comparison with those observed in the INCA campaign (Sect. 3). The altitude dependence in the Gary formula was derived from data at two narrow altitude regions (one is centered at $19.2 \mathrm{~km}$, and the other is centered at $11.4 \mathrm{~km}$ ), and it is not clear whether this can be extended to higher altitudes, due to wave breaking, for example. Given the important role that temperature perturbations play in cirrus cloud formation (Sect. 4.2), we therefore see a timely need for a refined parameterization of mesoscale motions in global models. A refined approach will require not only a better way to parameterize mesoscale temperature perturbations, but also a better way to parameterize the cooling rate or vertical velocity. The relationship between the mesoscale temperature perturbation and cooling rate used in Eq. (4) is derived from observations at $\mathrm{NH}$ midlatitudes, and may not represent other locations. Subgrid vertical velocity and temperature perturbations from orographic wave forcing have been derived by Joos et al. (2008) and Dean et al. (2007), respectively, to study orographic cirrus clouds. A better way to treat orographic cirrus in our model would be to combine the treatments in Joos et al. (2008) and Dean et al. (2007) to predict both the subgrid-scale temperature perturbation and the vertical velocity.

Simulated ice crystal number concentrations at lower temperatures $(<205 \mathrm{~K})$ are overestimated by 1 or 2 orders of magnitude when only the homogeneous freezing is included. The addition of heterogeneous IN from $10 \%$ of soot and dust particles improves the comparison with the observations. This suggests that the heterogeneous freezing is needed to reproduce the observed ice crystal number concentrations at lower temperatures. In our sensitivity tests, we assumed soot and dust particles have the same freezing capabilities, and used them as surrogates for heterogeneous IN in the real atmosphere. Atmospheric measurements showed that there were very few soot or dust particles in crystal residues near the tropical tropopause (Froyd et al., 2010), though biomass burning soot particles may act as IN to some degree (Petters et al., 2009; DeMott et al., 2009). Recent studies point to the potential roles of solid ammonium (Abbatt et al., 2006; Jensen et al., 2010) and organic glassy aerosols (Murray et al., 2010) as heterogeneous IN at low temperatures. In our sensitivity tests, we applied the same freezing fraction to dust and soot particles at all temperatures. As shown in Phillips et al. (2008), aerosol particles may have an increased freezing fraction at lower temperatures. This could bring our predicted ice number concentrations into better agreement with observations. However, further improvement in the understanding of heterogeneous IN in the atmosphere and their representation in global models is needed in order to improve the representation of ice number concentrations.

In an atmosphere dominated by homogeneous freezing, as in the HOM and HMHT_0.01IN cases, adding heterogeneous IN decreases ice crystal concentrations and increases cirrus cloud fraction. This explains the $30 \%$ decrease in simulated column-integrated ice crystal concentration from the HOM case to the HMHT_0.01IN case, as well as the $63 \%$ decrease from the HMHT_0.01IN case to the HMHT_0.1IN case. On the other hand, in an atmosphere dominated by heterogeneous freezing, as in the HMHT_0.1IN case, adding heterogeneous IN increases the ice crystal number concentration and has little effect on the cirrus cloud fraction. This explains the doubling of the simulated column-integrated ice crystal number concentration in the HMHT_1IN case compared with that in the HMHT_0.1IN case.

Changes in the ice crystal number concentration and cirrus cloud fraction from heterogeneous IN affect ice crystal radius, ice water content, low level liquid clouds, and water vapor in the atmosphere. More ice crystals lead to smaller ice crystal radii and smaller ice settling velocities. This leads to not only more ice water and more water vapor in the upper troposphere, but also to a more cloudy and more moist lower troposphere with less precipitation. The increasing low level clouds and decreasing precipitation with increasing cirrus clouds is associated with decreased convective activity, as evident from decreased convective precipitation rate.

The net change in cloud forcing from heterogeneous IN is less sensitive to changes in ice crystal number concentration (a maximum change of $0.49 \mathrm{~W} / \mathrm{m}^{2}$ in the net cloud forcing is simulated from the HMHT_0.01IN case to the HMHT_1IN case) because changes in both longwave and shortwave cloud forcing tend to cancel. The net flux changes at the TOA are mainly controlled by the change in upper tropospheric water vapor which closely follows the change in cirrus clouds (more ice crystals and more high level cloud amount lead to more warming). A maximum change of $1.7 \mathrm{~W} / \mathrm{m}^{2}$ is simulated from the HMHT_0.01IN case to the HMHT_1IN case, where the net cloud forcing change contributes $0.49 \mathrm{~W} / \mathrm{m}^{2}$ to this change, and the remaining $1.21 \mathrm{~W} / \mathrm{m}^{2}$ is caused mostly by the changes in the greenhouse effects of water vapor. The large change in the greenhouse effect of water vapor may point to a problem in studies of aerosol indirect effects on cirrus clouds that only examine the change in cloud forcing.

Changes in mesoscale temperature perturbations also change ice crystal number concentrations significantly. Column-integrated ice crystal number concentrations increase by $50 \%$ from the HMHT_0.01IN case to the HMHT_1.25 $d T$ case when the mesoscale temperature perturbation is increased by $25 \%$, while it decreases by $33 \%$ from the HMHT_0.01IN case to the HMHT_0.75 $d T$ case when the mesoscale temperature perturbation decreases by $25 \%$. Changes in ice crystal number concentrations, and radiative fluxes from a $25 \%$ change in the temperature perturbation have a magnitude that is similar to those caused 
by a factor of 10 change in the heterogeneous IN concentrations. This reinforces the importance of having a better representation of mesoscale dynamic forcing in the treatment of cirrus clouds and in studies of the indirect effects of aerosols on cirrus clouds (Haag and Kärcher, 2004).

In this study, the KB08 scheme is extended to include a simplified representation of both homogeneous freezing and heterogeneous freezing. The challenge in representing both homogeneous and heterogeneous freezing in GCMs is to resolve or parameterize the supersaturation levels which are critical to predicting whether homogeneous or heterogeneous freezing occurs. This is a difficult task, given the large GCM time step. Separately tracking the cirrus cloud fractions generated from homogeneous freezing and heterogeneous freezing may be helpful, but this may not be enough to solve the challenge of predicting the correct supersaturation levels in GCMs.

In this study, the prognostic cirrus cloud fraction is not advected. This simplification can potentially impose a physical inconsistency between the simulated cloud fraction, and the advected moisture and condensate fields, which may overestimate sublimation and affect relative humidity and ice crystal number concentrations in the upper troposphere. But since condensate fields are sublimated when they advect into the clear sky part of an adjacent grid, and since our cloud fraction responds in a physical way to the increase or decrease in moisture due to advection or sublimation, this potential inconsistency does not cause the results to become obviously unphysical. We note that many state of the art global climate models still do not have physically consistent treatments for all clouds.

It would be interesting to quantify the potential effects of this simplification, but this is difficult given the current model configuration. The main difficulty comes from the diagnostic treatment of cloud fraction in warm and mixedphase clouds (warmer than $-35^{\circ} \mathrm{C}$ ) and the lack of a consistent treatment for cloud formation in these clouds. If cloud fraction is advected, the advected cloud fraction cannot be used in warm and mixed-phased clouds without changing the parameterization of cloud formation in these clouds, since cloud fraction in warm and mixed-phase clouds is currently diagnosed. We attempted to advect only the cirrus cloud fraction. But this introduced an inconsistency which occurred at the boundary between mixed-phase clouds and cirrus clouds. When only cirrus cloud fraction is advected, cloud fraction can be added or subtracted from cirrus clouds in an adjacent grid zone, but the mixed-phase clouds in the adjacent grids are not decreased or increased. It is not clear whether the mixed-phase cloud fraction is somehow implicitly decreased or increased when only cirrus cloud fraction is advected since the warming/cooling and drying/moistening associated with the large scale transport may change relative humidity and result in changes in the cloud fraction of the mixed-phase clouds. In a test case, we advected cloud fraction for all clouds (for the homogeneous freezing case), but the advected cloud fraction was only used in cirrus clouds. The model was integrated for 3 years. Including advection of the cirrus cloud fraction increases the high level cloud fraction from $35 \%$ to $39 \%$, increases the column-integrated ice crystal number concentration from $0.090 \times 10^{10} \mathrm{~m}^{-2}$ to $0.170 \times 10^{10} \mathrm{~m}^{-2}$, and increases the longwave cloud forcing by $4 \mathrm{~W} / \mathrm{m}^{2}$. This suggests that advecting cloud fraction can be quite important. But given the inconsistencies between cirrus and mixed-phase clouds introduced by this approach, we have to be cautious in explaining these results. To include the advection of cloud fraction in a physically consistent manner for all clouds, a prognostic cloud fraction scheme for all clouds is needed. Such an addition is beyond the scope of this study. We expect to revisit this issue in the future when a prognostic cloud fraction treatment for other clouds is available in the NCAR CAM model.

\section{Appendix A}

\section{Equations used in the cirrus cloud scheme}

The key equations used in the cirrus cloud scheme of KB08 are listed in this Appendix, and readers are referred to KB08 for details.

The PDF of clear sky temperature is approximated by a constrained normal distribution with mean temperature $\left(T_{0}\right)$ and standard deviation $\delta T$ :

$$
\frac{d P_{T}}{d T}=\frac{1}{N_{T}} \frac{1}{\delta T} \frac{1}{\sqrt{2 \pi}} \exp \left\{\frac{-\left(T-T_{0}\right)^{2}}{2 \delta T^{2}}\right\},
$$

where $d P_{T} / d T=0$ outside of $T_{0} \pm 3 \delta T$ and $N_{T}$ is a normalization factor accounting for the finite limits over which Eq. (A1) is defined.

By using the saturation vapor pressure over pure hexagonal ice which is calculated based on Murphy and Koop (2005), the PDF of clear sky temperature is then transformed into the PDF of clear sky saturation ratio $(S)$ :

$$
\begin{aligned}
& \frac{d P_{S}}{d S}=\frac{1}{N_{S}} \frac{1}{\sigma_{S} \sqrt{2 \pi}} \frac{1}{S \ln ^{2}(S / \alpha)} \\
& \times \exp \left[-\beta_{S}\left\{\frac{1}{\ln (S / \alpha)}-\frac{1}{\ln \left(S_{0} / \alpha\right)}\right\}^{2}\right],
\end{aligned}
$$

where $\beta_{S}=1 /\left(2 \sigma_{S}^{2}\right), \quad \sigma_{S}=\delta T / \theta, \quad \theta=6132.9 \mathrm{~K}, \quad \alpha=\mathrm{p}_{v} / \phi$, $\phi=3.4452 \times 10^{10} \mathrm{hPa}$, and $p_{v}$ is the water vapor partial pressure. $S_{0}$ is the mean clear sky saturation ratio and $N_{S}$ is a normalization factor, which is calculated as

$$
\begin{aligned}
& N_{S}=\frac{1}{2}\left(\operatorname{erf}\left[\sqrt{\beta_{S}}\left\{\frac{1}{\ln \left(S_{0} / \alpha\right)}-\frac{1}{\ln \left(S_{3+} / \alpha\right)}\right\}\right]\right) \\
& -\operatorname{erf}\left[\sqrt{\beta_{S}}\left\{\frac{1}{\ln \left(S_{0} / \alpha\right)}-\frac{1}{\ln \left(S_{3-} / \alpha\right)}\right\}\right],
\end{aligned}
$$


where $S_{3+}$ and $S_{3-}$ are the upper and lower bounds of $S$ at which $d P_{s} / d S$ is defined (i.e., $d P_{S} / d S=0$ outside of $\left[S_{3-}\right.$, $S_{3+}$ ) and $S_{3 \pm}$ is calculated as:

$S_{3 \pm} \approx S_{0} \exp \left(\frac{ \pm 3 \delta T \theta}{T_{0}^{2}}\right)$.

Here, $\operatorname{erf}(x)$ is the error function and is defined as:

$\operatorname{erf}(x)=(2 / \sqrt{\pi}) \int_{0}^{x} \exp \left(-t^{2}\right) d t$

The in-cloud vapor deposition/evaporation is calculated as

$\left(\frac{\partial q_{v c}}{\partial t}\right)_{\mathrm{dep}}=-4 \pi D N_{i} r \beta C \phi\left(q_{v c}-q_{\mathrm{sat}}\right)=-\frac{q_{v c}-q_{\mathrm{sat}}}{\tau_{s}}$,

where $N_{i}$ is the in-cloud ice crystal number concentration, $r$ is the volume mean radius, $D$ is the diffusion coefficient of water molecules in air, $C$ and $\phi$ are the ice crystal capacitance and ventilation factors, $\beta$ accounts for gas kinetic corrections, and $\tau_{s}$ is the instantaneous relaxation time-scale given by:

$\tau_{s}=\frac{1}{4 \pi D N_{i} r \beta C \phi}$.

$C, \phi$, and $\beta$ are set equal to unity in this study. Integrating Eq. (A6) over a time step $\tau$ yields the vapor deposition formula given in Eq. (12).

The PDF of the in-cloud ice water content $\left(q_{i}\right)\left(d P_{q i} / d q_{i}\right)$ is represented by the following formula:

$q_{i} \frac{d P_{q_{i}}}{d q_{i}}=\frac{2}{\sqrt{\pi}}\left(\frac{q_{i}}{q_{i 0}}\right) \exp \left\{-\left(\frac{q_{i}}{q_{i 0}}\right)^{2}\right\}, \quad q_{i 0}=\sqrt{\pi} \bar{q}_{i}$,

(A8) where $\bar{q}_{i}$ is the mean ice water content. This PDF of in-cloud ice water content was shown to be a good approximation of the cirrus ice water content observed over Punta Arenas, Chile (Ström et al., 2003; KB08). The PDF of incloud water vapor is assumed to be a homogeneous distribution in the form of a delta function. Therefore, the PDF of the total water mass mixing ratio in cloudy areas $\left(q_{\mathrm{totc}}\right)$ is:

$\frac{d P_{q_{\mathrm{totc}}}}{d q_{\mathrm{totc}}}=\frac{2}{\sqrt{\pi}} \frac{1}{q_{0}} \exp \left\{-\left(\frac{q_{\mathrm{totc}}-q_{v c}}{q_{0}}\right)^{2}\right\}, \quad q_{0}=\sqrt{\pi} \frac{q_{i}}{a}$,

where $q_{i} / a$ denotes the simulated in-cloud ice mass mixing ratio and $q_{\text {totc }} \geq q_{v c}$. This PDF for the total water mixing ratio is used to calculate changes in cloud fraction and ice water content by Eqs. (9) and (10), respectively.

\section{Supplementary material related to this article is available online at: \\ http://www.atmos-chem-phys.net/10/5449/2010/ acp-10-5449-2010-supplement.pdf.}

Acknowledgements. We thank Xiaohong Liu at Pacific Northwest National Laboratory for many helpful discussions regarding the cirrus cloud treatment in LIU07 and Yuxing Yun at the University of Michigan for the discussions regarding the ice nucleation treatment in mixed-phase clouds. We are grateful to Richard Easter, Steven Ghan and Phil Rash for helpful discussions regarding advecting cloud fraction in global climate models. We also would like to thank Bruce Gary, Christopher Hoyle and Stephen Eckermann for helpful discussions regarding the treatment of mesoscale temperature perturbations. We are grateful to Peter Spichtinger for his helpful comments and for providing us the MLS ISSR data, and Martina Krämer for the observational data used in Fig. 5. Three anonymous reviewers and Bernd Kärcher provided thoughtful and constructive comments, which help improve the manuscript substantially. This work was funded in part by NSF projects ATM 0333016 and ATM 0609836. Computer time was provided by the NCAR CISL facility. Work on this project while the first author was at Pacific Northwest National Laboratory was supported by the US Department of Energy's Office of Biological and Environmental Research as part of the Atmospheric System Research (ASR) Program.

Edited by: J. Quaas

\section{References}

Abbatt, J. P. D., Benz, S., Cziczo, D. J., Kanji, Z., Lohmann, U., and Möhler, O.: Solid ammonium sulfate aerosols as ice nuclei: A pathway for cirrus cloud formation, Science, 313, 1770-1773, doi:10.1126/science.1129726, 2006.

Abdul-Razzak, H. and Ghan, S. J.: A parameterization of aerosol activation 2. Multiple aerosol types, J. Geophys. Res., 105, 6837-6844, 2000.

Abdul-Razzak, H. and Ghan, S. J.: A parameterization of aerosol activation 3. Sectional representation, J. Geophys. Res., 107, 4026, doi:10.1029/2001JD000 483, 2002.

Andres, R. J. and Kasgnoc, A. D.: A time-averaged inventory of subaerial volcanic sulfur emissions, J. Geophys. Res., 103, 25251-25261, 1998.

Bacmeister, J. T., Eckermann, S. D., Tsias, A., Carslaw, K. S., and Peter, T.: Mesoscale temperature fluctuations induced by a spectrum of gravity waves: A comparison of parameterizations and their impact on stratospheric microphysics, J. Atmos. Sci., 56, 1913-1924, 1999.

Beheng, K. D.: A parameterization of warm cloud microphysical conversion processes, Atmos. Res., 33, 193-206, 1994.

Boville, B. A., Rasch, P. J., Hack, J. J., and McCaa, J. R.: Representation of clouds and precipitation processes in the Community Atmosphere Model version 3 (CAM3), J. Climate, 19, 21842198, 2006.

Cantrell, W. and Heymsfield, A.: Production of ice in tropospheric clouds - A review, Bull. Amer. Meteor. Soc., 86, 795-807, 2005.

Chen, Y. L., Kreidenweis, S. M., McInnes, L. M., Rogers, D. C., and DeMott, P. J.: Single particle analyses of ice nucleating aerosols in the upper troposphere and lower stratosphere, Geophys. Res. Lett., 25, 1391-1394, 1998.

Chen, T., Rossow, W. B., and Zhang, Y. C.: Radiative effects of cloud-type variations, J. Climate, 13, 264-286, 2000. 
Chen, Y.: Aerosol indirect effects on clouds and global climate, $\mathrm{PhD}$, Department of Atmospheric, Oceanic, and Space Sciences, University of Michigan, Ann Arbor, MI, USA, 218 pp., 2006.

Collins, W. D.: Parameterization of generalized cloud overlap for radiative calculations in general circulation models, J. Atmos. Sci., 58, 3224-3242, 2001.

Collins, W. D., Bitz, C. M., Blackmon, M. L., Bonan, G. B., Bretherton, C. S., Carton, J. A., Chang, P., Doney, S. C., Hack, J. J., Henderson, T. B., Kiehl, J. T., Large, W. G., McKenna, D. S., Santer, B. D., and Smith, R. D.: The Community Climate System Model version 3 (CCSM3), J. Climate, 19, 2122-2143, 2006.

Collins, W. D., Rasch, P. J., Boville, B. A., Hack, J. J., McCaa, J. R., Williamson, D. L., Briegleb, B. P., Bitz, C. M., Lin, S. J., and Zhang, M. H.: The formulation and atmospheric simulation of the Community Atmosphere Model version 3 (CAM3), J. Climate, 19, 2144-2161, 2006.

Cziczo, D. J., Murphy, D. M., Hudson, P. K., and Thomson, D. S.: Single particle measurements of the chemical composition of cirrus ice residue during CRYSTAL-FACE, J. Geophys. Res., 109, D04201, doi:10.1029/2003JD004032, 2004.

Cziczo, D. J., Stetzer O., Worringen A., Ebert M., Weinbruch S., Kamphus M., Gallavardin S. J., Curtius J., Borrmann S., Froyd K. D., Mertes S., Möhler O., and Lohmann U: Inadvertent climate modification due to anthropogenic lead, Nature Geosci., 2, 333-336, doi:10.1038/NGEO499, 2009.

de Reus, M., Dentener, F., Thomas, A., Borrmann, S., Ström, J., and Lelieveld, J.: Airborne observations of dust aerosol over the North Atlantic Ocean during ACE 2: Indications for heterogeneous ozone destruction, J. Geophys. Res., 105, 15263-15275, 2000.

Dean, S. M., Flowerdew, J., Lawrence, B. N., and Eckermann, S. D.: Parameterisation of orographic cloud dynamics in a GCM, Climate Dyn.. 28, 581-597, doi:10.1007/s00382-006-0202-0, 2007.

DeMott, P. J., Rogers, D. C., and Kreidenweis, S. M.: The susceptibility of ice formation in upper tropospheric clouds to insoluble aerosol components, J. Geophys. Res., 102, 19575-19584, 1997.

DeMott, P. J., Sassen, K., Poellot, M. R., Baumgardner, D., Rogers, D. C., Brooks, S. D., Prenni, A. J., and Kreidenweis, S. M.: African dust aerosols as atmospheric ice nuclei, Geophys. Res. Lett., 30, 1732, doi:10.1029/2003GL017410, 2003.

DeMott, P. J., Petters, M. D., Prenni, A. J., Carrico, C. M., Kreidenweis, S. M., Collett, J. L. Jr., and Moosmüller, H.: Ice nucleation behavior of biomass combustion particles at cirrus temperatures, J. Geophys. Res., 114, D16205, doi:10.1029/2009JD012036, 2009.

Eyers, C. J., Norman, P., Middel, J., Plohr, M., Michot, S., Atkinson, K., and Christou, R. A.: AERO2k Global Aviation Emissions Inventories for 2002 and 2025, QinetiQ/-4/01113, available online at: http://www.cate.mmu.ac.uk/reports_aero2k.asp? chg $=$ projects \&chg2=2, 2004 .

Ferraro, R. R., Weng, F. Z., Grody, N. C., and Basist, A.: An eightyear (1987-1994) time series of rainfall, clouds, water vapor, snow cover, and sea ice derived from SSM/I measurements, Bull. Amer. Meteor. Soc., 77, 891-905, 1996.

Forster, P. M. D. and Shine, K. P.: Assessing the climate impact of trends in stratospheric water vapor, Geophys. Res. Lett., 29, 1086, doi:10.1029/2001g1013909, 2002.

Fritts, D. C. and Alexander, M. J.: Gravity wave dynamics and effects in the middle atmosphere, Rev. Geophys., 41, 1003, doi:10.1029/2001rg000106, 2003.

Froyd, K. D., Murphy, D. M., Lawson, P., Baumgardner, D., and Herman, R. L.: Aerosols that form subvisible cirrus at the tropical tropopause, Atmos. Chem. Phys., 10, 209-218, 2010, http://www.atmos-chem-phys.net/10/209/2010/.

Gallagher, M. W., Connolly, P. J., Whiteway, J., Figueras-Nieto, D., Flynn, M., Choularton, T. W., Bower, K. N., Cook, C., Busen, R., and Hacker, J.: An overview of the microphysical structure of cirrus clouds observed during EMERALD-1, Quart. J. Roy. Meteor. Soc., 131, 1143-1169, doi:10.1256/Qj.03.138, 2005.

Gary, B. L.: Mesoscale temperature fluctuations in the stratosphere, Atmos. Chem. Phys., 6, 4577-4589, 2006, http://www.atmos-chem-phys.net/6/4577/2006/.

Gary, B. L.: Mesoscale temperature fluctuations in the Southern Hemisphere stratosphere, Atmos. Chem. Phys., 8, 4677-4681, 2008, http://www.atmos-chem-phys.net/8/4677/2008/.

Gayet, J. F., Auriol, F., Minikin, A., Ström, J., Seifert, M., Krejci, R., Petzold, A., Febvre, G., and Schumann, U.: Quantitative measurement of the microphysical and optical properties of cirrus clouds with four different in situ probes: Evidence of small ice crystals, Geophys. Res. Lett., 29, 2230, doi:10.1029/2001g1014342, 2002.

Gayet, J. F., Ovarlez, J., Shcherbakov, V., Ström, J., Schumann, U., Minikin, A., Auriol, F., Petzold, A., and Monier, M.: Cirrus cloud microphysical and optical properties at southern and northern midlatitudes during the INCA experiment, J. Geophys. Res., 109, D20206, doi:10.1029/2004jd004803, 2004.

Gayet, J. F., Shcherbakov, V., Mannstein, H., Minikin, A., Schumann, U., Ström, J., Petzold, A., Ovarlez, J., and Immler, F.: Microphysical and optical properties of midlatitude cirrus clouds observed in the southern hemisphere during INCA, Q. J. Roy. Meteor. Soc., 132, 2719-2748, doi:10.1256/Qj.05.162, 2006.

Gettelman, A., Morrison, H., and Ghan, S. J.: A new two-moment bulk stratiform cloud microphysics scheme in the community atmosphere model, version 3 (CAM3). Part II: Single-colunm and global results, J. Climate, 21, 3660-3679, 2008.

Ghan, S., Laulainen, N., Easter, R., Wagener, R., Nemesure, S., Chapman, E., Zhang, Y., and Leung, R.: Evaluation of aerosol direct radiative forcing in MIRAGE, J. Geophys. Res., 106, 52955316, 2001.

Gierens, K., Schumann, U., Helten, M., Smit, H., and Marenco, A.: A distribution law for relative humidity in the upper troposphere and lower stratosphere derived from three years of MOZAIC measurements, Ann. Geophys., 17, 1218-1226, 1999, http://www.ann-geophys.net/17/1218/1999/.

Gierens, K.: On the transition between heterogeneous and homogeneous freezing, Atmos. Chem. Phys., 3, 437-446, 2003, http://www.atmos-chem-phys.net/3/437/2003/.

Ginoux, P., Chin, M., Tegen, I., Prospero, J. M., Holben, B., Dubovik, O., and Lin, S. J.: Sources and distributions of dust aerosols simulated with the GOCART model, J. Geophys. Res., 106, 20255-20273, 2001.

Gong, S. L., Barrie, L. A., and Blanchet, J. P.: Modeling sea-salt aerosols in the atmosphere .1. Model development, J. Geophys. Res., 102, 3805-3818, 1997.

Grabowski, W. W.: Cloud microphysics and the tropical climate: Cloud-resolving model perspective, J. Climate, 13, 2306-2322, 2000.

Greenwald, T. J., Stephens, G. L., Vonderhaar, T. H., and Jackson, 
D. L.: A physical retrieval of cloud liquid water over the global oceans using special sensor microwave imager (SSM/I) observations, J. Geophys. Res., 98, 18471-18488, 1993.

Haag, W., Kärcher, B., Ström, J., Minikin, A., Lohmann, U., Ovarlez, J., and Stohl, A.: Freezing thresholds and cirrus cloud formation mechanisms inferred from in situ measurements of relative humidity, Atmos. Chem. Phys., 3, 1791-1806, 2003, http://www.atmos-chem-phys.net/3/1791/2003/.

Haag, W. and Kärcher, B.: The impact of aerosols and gravity waves on cirrus clouds at midlatitudes, J. Geophys. Res., 109, D12202, doi:10.1029/2004JD004579, 2004.

Hall, W. D. and Pruppacher, H. R.: Survival of Ice Particles Falling from Cirrus Clouds in Subsaturated Air, J. Atmos. Sci., 33, 1995-2006, 1976.

Han, Q. Y., Rossow, W. B., and Lacis, A. A.: Near-Global survey of effective droplet radii in liquid water clouds using ISCCP data, J. Climate, 7, 465-497, 1994.

Han, Q. Y., Rossow, W. B., Chou, J., and Welch, R. M.: Global variation of column droplet concentration in low-level clouds, Geophys. Res. Lett., 25, 1419-1422, 1998.

Hendricks, J., Kärcher, B., Dopelheuer, A., Feichter, J., Lohmann, U., and Baumgardner, D.: Simulating the global atmospheric black carbon cycle: a revisit to the contribution of aircraft emissions, Atmos. Chem. Phys., 4, 2521-2541, 2004, http://www.atmos-chem-phys.net/4/2521/2004/.

Hendricks, J., Kärcher, B., Lohmann, U., and Ponater, M.: Do aircraft black carbon emissions affect cirrus clouds on the global scale?, Geophys. Res. Lett., 32, L12814, doi:10.1029/2005g1022740, 2005.

Heymsfield, A. J.: Precipitation development in stratiform ice clouds - microphysical and dynamical study, J. Atmos. Sci., 34, 367-381, 1977.

Heymsfield, A. J. and Sabin, R. M.: Cirrus crystal nucleation by homogeneous freezing of solution droplets, J. Atmos. Sci., 46, 2252-2264, 1989.

Hoyle, C. R., Luo, B. P., and Peter, T.: The origin of high ice crystal number densities in cirrus clouds, J. Atmos. Sci., 62, 2568-2579, 2005.

Immler, F., Kruger, K., Fujiwara, M., Verver, G., Rex, M., and Schrems, O.: Correlation between equatorial Kelvin waves and the occurrence of extremely thin ice clouds at the tropical tropopause, Atmos. Chem. Phys., 8, 4019-4026, 2008,

http://www.atmos-chem-phys.net/8/4019/2008/.

Ito, A. and Penner, J. E.: Historical emissions of carbonaceous aerosols from biomass and fossil fuel burning for the period 1870-2000, Global Biogeochem. Cycles, 19, GB2028, doi:10.1029/2004GB002374, 2005.

Jakob, C.: Ice clouds in numerical weather prediction models: Progress, problems, and prospects, in: Cirrus, edited by: Lynch, D. K., Sassen, K., Starr, D. O. C., and Stephens, G., Oxford University Press, New York, USA, 327-345, 2002.

Jensen, E. J., Toon, O. B., Westphal, D. L., Kinne, S., and Heysmfield, A. J.: Microphysical modeling of cirrus .1. Comparison with 1986 FIRE IFO measurements, J. Geophys. Res., 99, 10421-10442, 1994.

Jensen, E. J. and Toon, O. B.: The potential impact of soot particles from aircraft exhaust on cirrus clouds, Geophys. Res. Lett., 24, 249-252, 1997.

Jensen, E. and Pfister, L.: Transport and freeze-drying in the tropical tropopause layer, J. Geophys. Res., 109, D02207, doi:10.1029/2003JD004022, 2004.

Jensen, E. J., Pfister, L., Bui, T. V., Lawson, P., Baker, B., Mo, Q., Baumgardner, D., Weinstock, E. M., Smith, J. B., Moyer, E. J., Hanisco, T. F., Sayres, D. S., St Clair, J. M., Alexander, M. J., Toon, O. B., and Smith, J. A.: Formation of large (similar or equal to $100 \mu \mathrm{m}$ ) ice crystals near the tropical tropopause, Atmos. Chem. Phys., 8, 1621-1633, 2008,

http://www.atmos-chem-phys.net/8/1621/2008/.

Jensen, E. J., Pfister, L., Bui, T. P., Lawson, P., and Baumgardner, D.: Ice nucleation and cloud microphysical properties in tropical tropopause layer cirrus, Atmos. Chem. Phys., 10, 1369-1384, 2010, http://www.atmos-chem-phys.net/10/1369/2010/.

Joos, H., Spichtinger, P., Lohmann, U., Gayet, J. F., and Minikin, A.: Orographic cirrus in the global climate model echam5, J. Geophys. Res., 113, D18205, doi:10.1029/2007jd009605, 2008.

Kärcher, B., and Lohmann, U.: A parameterization of cirrus cloud formation: Homogeneous freezing of supercooled aerosols, J. Geophys. Res., 107, 4010, doi:10.1029/2001jd000470, 2002.

Kärcher, B. and Ström, J.: The roles of dynamical variability and aerosols in cirrus cloud formation, Atmos. Chem. Phys., 3, 823838, 2003, http://www.atmos-chem-phys.net/3/823/2003/.

Kärcher, B. and Burkhardt, U.: A cirrus cloud scheme for general circulation models, Quart. J. Roy. Meteor. Soc., 134, 1439-1461, doi:10.1002/Qj.301, 2008.

Kettle, A. J. and Andreae, M. O.: Flux of dimethylsulfide from the oceans: A comparison of updated data seas and flux models, J. Geophys. Res., 105, 26793-26808, 2000.

Kiehl, J. T., and Trenberth, K. E.: Earth's annual global mean energy budget, Bull. Amer. Meteor. Soc., 78, 197-208, 1997.

King, M. D., Menzel, W. P., Kaufman, Y. J., Tanre, D., Gao, B. C., Platnick, S., Ackerman, S. A., Remer, L. A., Pincus, R., and Hubanks, P. A.: Cloud and aerosol properties, precipitable water, and profiles of temperature and water vapor from MODIS, Ieee Trans. Geosci. Remote Sens., 41, 442-458, doi:10.1109/Tgrs.2002.808226, 2003.

Kinne, S., Schulz, M., Textor, C., Guibert, S., Balkanski, Y., Bauer, S. E., Berntsen, T., Berglen, T. F., Boucher, O., Chin, M., Collins, W., Dentener, F., Diehl, T., Easter, R., Feichter, J., Fillmore, D., Ghan, S., Ginoux, P., Gong, S., Grini, A., Hendricks, J. E., Herzog, M., Horowitz, L., Isaksen, L., Iversen, T., Kirkavag, A., Kloster, S., Koch, D., Kristjansson, J. E., Krol, M., Lauer, A., Lamarque, J. F., Lesins, G., Liu, X., Lohmann, U., Montanaro, V., Myhre, G., Penner, J. E., Pitari, G., Reddy, S., Seland, O., Stier, P., Takemura, T., and Tie, X.: An AeroCom initial assessment - optical properties in aerosol component modules of global models, Atmos. Chem. Phys., 6, 1815-1834, 2006, http://www.atmos-chem-phys.net/6/1815/2006/.

Koop, T., Luo, B. P., Tsias, A., and Peter, T.: Water activity as the determinant for homogeneous ice nucleation in aqueous solutions, Nature, 406, 611-614, 2000.

Krämer, M., Schiller, C., Afchine, A., Bauer, R., Gensch, I., Mangold, A., Schlicht, S., Spelten, N., Sitnikov, N., Borrmann, S., de Reus, M., and Spichtinger, P.: Ice supersaturations and cirrus cloud crystal numbers, Atmos. Chem. Phys., 9, 3505-3522, 2009, http://www.atmos-chem-phys.net/9/3505/2009/.

Lee, D.S., Owen, B., Graham, A., Fichter, C., Lim, L.L., and Dimitriu, D.: Study of the allocation of aviation emissions from scheduled air traffic - present day and historical, Final Report 
to DEFRA Global Atmosphere Division, Manchester Metropolitan University, available online at: http://www.cate.mmu.ac.uk/ project_view.asp?chg=projects\&chg2=2\&id=2, 62 pp., 2005,

Li, J. L., Waliser, D. E., Jiang, J. H., Wu, D. L., Read, W., Waters, J. W., Tompkins, A. M., Donner, L. J., Chern, J. D., Tao, W. K., Atlas, R., Gu, Y., Liou, K. N., Del Genio, A., Khairoutdinov, M., and Gettelman, A.: Comparisons of EOS MLS cloud ice measurements with ECMWF analyses and GCM simulations: Initial results, Geophys. Res. Lett., 32, L18710, doi:10.1029/2005GL023788 2005.

Liu, X. H., and Penner, J. E.: Effect of Mount Pinatubo $\mathrm{H}_{2} \mathrm{SO}_{4} / \mathrm{H}_{2} \mathrm{O}$ aerosol on ice nucleation in the upper troposphere using a global chemistry and transport model, J. Geophys. Res., 107, 4141, doi:10.1029/2001JD000455 2002.

Liu, X. H., and Penner, J. E.: Ice nucleation parameterization for global models, Meteor. Z., 14, 499-514, doi:10.1127/09412948/2005/0059, 2005.

Liu, X., Penner, J. E., Ghan, S. J., and Wang, M.: Inclusion of ice microphysics in the NCAR community atmospheric model version 3 (CAM3), J. Climate, 20, 4526-4547, 2007a.

Liu, X. H., Xie, S. C., and Ghan, S. J.: Evaluation of a new mixedphase cloud microphysics parameterization with CAM3 singlecolumn model and M-PACE observations, Geophys. Res. Lett., 34, L23712, doi:10.1029/2007GL031446 2007b.

Liu, X. H., Penner, J. E., and Wang, M. H.: Influence of anthropogenic sulfate and black carbon on upper tropospheric clouds in the NCAR CAM3 model coupled to the IMPACT global aerosol model, J. Geophys. Res., 114, D03204, doi:10.1029/2008JD010492, 2009.

Lohmann, U., Feichter, J., Chuang, C. C., and Penner, J. E.: Prediction of the number of cloud droplets in the ECHAM GCM, J. Geophys. Res., 104, 9169-9198, 1999.

Lohmann, U., and Kärcher, B.: First interactive simulations of cirrus clouds formed by homogeneous freezing in the ECHAM general circulation model, J. Geophys. Res., 107, 4105, doi:10.1029/2001JD000767, 2002.

Lohmann, U., Stier, P., Hoose, C., Ferrachat, S., Kloster, S., Roeckner, E., and Zhang, J.: Cloud microphysics and aerosol indirect effects in the global climate model ECHAM5-HAM, Atmos. Chem. Phys., 7, 3425-3446, 2007,

http://www.atmos-chem-phys.net/7/3425/2007/.

Lohmann, U., Spichtinger, P., Jess, S., Peter, T., and Smit, H.: Cirrus cloud formation and ice supersaturated regions in a global climate model, Environ. Res. Lett., 3, 045022, doi:10.1088/17489326/3/4/045022, 2008.

Mace, G. G., Clothiaux, E. E., and Ackerman, T. P.: The composite characteristics of cirrus clouds: Bulk properties revealed by one year of continuous cloud radar data, J. Climate, 14, 2185-2203, 2001.

Marcolli, C., Gedamke, S., Peter, T., and Zobrist, B.: Efficiency of immersion mode ice nucleation on surrogates of mineral dust, Atmos. Chem. Phys., 7, 5081-5091, 2007, http://www.atmos-chem-phys.net/7/5081/2007/.

McFarquhar, G. M., Zhang, G., Poellot, M. R., Kok, G. L., Mccoy, R., Tooman, T., Fridlind, A., and Heymsfield, A. J.: Ice properties of single-layer stratocumulus during the Mixed-Phase Arctic Cloud Experiment: 1. Observations, J. Geophys. Res., 112, D24201, doi:10.1029/2007jd008633, 2007.

Meyers, M. P., P. J. DeMott, and W. R. Cotton: New primary ice nucleation parameterizations in an explicit cloud model, J. Appl. Meteor., 31, 708-721, 1992.

Möhler, O., Field, P. R., Connolly, P., Benz, S., Saathoff, H., Schnaiter, M., Wagner, R., Cotton, R., Krärmer, M., Mangold, A., and Heymsfield, A. J.: Efficiency of the deposition mode ice nucleation on mineral dust particles, Atmos. Chem. Phys., 6, 3007-3021, 2006,

http://www.atmos-chem-phys.net/6/3007/2006/.

Murphy, D. M., and Koop, T.: Review of the vapour pressures of ice and supercooled water for atmospheric applications, Q. J. Roy. Meteor. Soc., 131, 1539-1565, doi:10.1256/Qj.04.94, 2005.

Murray, B. J., Wilson, T. W., Dobbie, S., Cui, Z. Q., Al-Jumur, S. M. R. K., Mohler, O., Schnaiter, M., Wagner, R., Benz, S., Niemand, M., Saathoff, H., Ebert, V., Wagner, S., and Karcher, B.: Heterogeneous nucleation of ice particles on glassy aerosols under cirrus conditions, Nature Geosci., 3, 233-237, doi:10.1038/Ngeo817, 2010.

Penner, J. E., Andreae, M. O., Annegarn, H., Barrie, L., Feichter, J., Hegg, D., Jayaraman, A., Leaitch, R., Murphy, D., Nganga, J., and Pitari, G.: Aerosols, their Direct and Indirect Effects, in: Climate Change 2001: The Scientific Basis, Contribution of working group I to the Third Assessment Report of the Intergovernmental Panel on Climate Change, edited by: Houghton, J. T., Ding, Y., Griggs, D. J., Noguer, M., Van der Linden, P. J., Dai, X., Maskell, K., and Johnson, C. A., Cambridge University Press, New York, USA, 881, 2001.

Penner, J. E., Chen, Y., Wang, M., and Liu, X.: Possible influence of anthropogenic aerosols on cirrus clouds and anthropogenic forcing, Atmos. Chem. Phys., 9, 879-896, 2009,

http://www.atmos-chem-phys.net/9/879/2009/.

Petters, M. D., Parsons, M. T., Prenni, A. J., DeMott, P. J., Kreidenweis, S. M., Carrico, C. M., Sullivan, A. P.,. McMeeking, G. R., Levin, E., Wold, C. E., Collett, J. L. Jr., and Moosmüller, H.: Ice nuclei emissions from biomass burning, J. Geophys. Res., 114, D07209, doi:10.1029/2008JD011532, 2009.

Petzold, A. and Schröder, F. P.: Jet engine exhaust aerosol characterization, Aerosol Sci. Tech., 28, 62-76, 1998.

Phillips, V. T. J., DeMott, P. J., and Andronache, C.: An empirical parameterization of heterogeneous ice nucleation for multiple chemical species of aerosol, J. Atmos. Sci., 65, 2757-2783, doi:10.1175/2007jas2546.1, 2008.

Platnick, S., King, M. D., Ackerman, S. A., Menzel, W. P., Baum, B. A., Riedi, J. C., and Frey, R. A.: The MODIS cloud products: Algorithms and examples from Terra, IEEE Trans. Geosci. Remote Sens., 41, 459-473, 2003.

Pruppacher, H. R. and J. D. Klett: Microphysics of Cloud and Precipitation, Springer, New York, USA, 954 pp., 1997.

Pusechel, R. F., Blake, D. F., Snetsinger, K. G., Hansen, A. D. A., Verma, S., and Kato, K.: Black carbon (Soot) aerosol in the lower stratosphere and upper troposphere, Geophys. Res. Lett., 19, 1659-1662, 1992.

Quaas, J., Boucher, O., and Breon, F. M.: Aerosol indirect effects in POLDER satellite data and the Laboratoire de Meteorologie Dynamique-Zoom (LMDZ) general circulation model, J. Geophys. Res., 109, D08205, doi:10.1029/2003jd004317, 2004.

Quaas, J., Boucher, O., and Lohmann, U.: Constraining the total aerosol indirect effect in the LMDZ and ECHAM4 GCMs using MODIS satellite data, Atmos. Chem. Phys., 6, 947-955, 2006, http://www.atmos-chem-phys.net/6/947/2006/. 
Quinn, P. K. and Coffman, D. J.: Local closure during the First Aerosol Characterization Experiment (ACE 1): Aerosol mass concentration and scattering and backscattering coefficients, J. Geophys. Res., 103, 16575-16596, 1998.

Ramanathan, V. and Collins, W.: Thermodynamic regulation of ocean warming by cirrus clouds deduced from observations of the 1987 El-Nino, Nature, 351, 27-32, 1991.

Rasch, P. J. and Kristjansson, J. E.: A comparison of the CCM3 model climate using diagnosed and predicted condensate parameterizations, J. Climate, 11, 1587-1614, 1998.

Raval, A., and Ramanathan, V.: Observational determination of the greenhouse-effect, Nature, 342, 758-761, 1989.

Read, W. G., Waters, J. W., Wu, D. L., Stone, E. M., Shippony, Z., Smedley, A. C., Smallcomb, C. C., Oltmans, S., Kley, D., Smit, H. G. J., Mergenthaler, J. L., and Karki, M. K.: UARS microwave limb sounder upper tropospheric humidity measurement: Method and validation, J. Geophys. Res., 106, 3220732258, 2001.

Rossow, W. B. and Schiffer, R. A.: Advances in understanding clouds from ISCCP, Bull. Amer. Meteor. Soc., 80, 2261-2287, 1999.

Rotstayn, L. D., Ryan, B. F., and Katzfey, J. J.: A scheme for calculation of the liquid fraction in mixed-phase stratiform clouds in large-scale models, Mon. Weather Rev., 128, 1070-1088, 2000.

Rotstayn, L. D. and Liu, Y. G.: Sensitivity of the first indirect aerosol effect to an increase of cloud droplet spectral dispersion with droplet number concentration, J. Climate, 16, 3476-3481, 2003.

Sanderson, B. M., Piani, C., Ingram, W. J., Stone, D. A., and Allen, M. R.: Towards constraining climate sensitivity by linear analysis of feedback patterns in thousands of perturbed-physics GCM simulations, Climate Dyn.. 30, 175-190, 2008.

Schroder, F., Kärcher, B., Duroure, C., Ström, J., Petzold, A., Gayet, J. F., Strauss, B., Wendling, P., and Borrmann, S.: On the transition of contrails into cirrus clouds, J. Atmos. Sci., 57, 464-480, 2000.

Schulz, M., Textor, C., Kinne, S., Balkanski, Y., Bauer, S., Berntsen, T., Berglen, T., Boucher, O., Dentener, F., Guibert, S., Isaksen, I. S. A., Iversen, T., Koch, D., Kirkevag, A., Liu, X., Montanaro, V., Myhre, G., Penner, J. E., Pitari, G., Reddy, S., Seland, O., Stier, P., and Takemura, T.: Radiative forcing by aerosols as derived from the AeroCom present-day and pre-industrial simulations, Atmos. Chem. Phys., 6, 5225-5246, 2006, http://www.atmos-chem-phys.net/6/5225/2006/.

Seifert, M., Ström, J., Krejci, R., Minikin, A., Petzold, A., Gayet, J. F., Schumann, U., and Ovarlez, J.: In-situ observations of aerosol particles remaining from evaporated cirrus crystals: Comparing clean and polluted air masses, Atmos. Chem. Phys., 3, 10371049, 2003, http://www.atmos-chem-phys.net/3/1037/2003/.

Smith, W. L., Ackerman, S., Revercomb, H., Huang, H., DeSlover, D. H., Feltz, W., Gumley, L., and Collard, A.: Infrared spectral absorption of nearly invisible cirrus clouds, Geophys. Res. Lett., 25, 1137-1140, 1998.

Smith, S. J., Pitcher, H., and Wigley, T. M. L.: Global and regional anthropogenic sulfur dioxide emissions, Global Planet. Change, 29, 99-119, 2001.

Smith, S., Andres, R., Conception, L., and Lurz, J.: Historical sulfur dioxide emissions 1850-2000: Methods and resutls, JGCRI
Research report PNNL 14537, Paciific Northwest National Laboratory, Richland, WA, USA, 14537, 16 pp., 2004.

Spichtinger, P., Gierens, K., and Read, W.: The global distribution of ice-supersaturated regions as seen by the Microwave Limb Sounder, Quart. J. Roy. Meteor. Soc., 129, 3391-3410, 2003.

Stephens, G. L., Tsay, S. C., Stackhouse, P. W., and Flatau, P. J.: The relevance of the microphysical and radiative properties of cirrus clouds to climate and climatic feedback, J. Atmos. Sci., 47, 1742-1753, 1990.

Storelvmo, T., Kristjansson, J. E., and Lohmann, U.: Aerosol influence on mixed-phase clouds in CAM-Oslo, J. Atmos. Sci., 65, 3214-3230, doi:10.1175/2008jas2430.1, 2008.

Ström, J. and Heintzenberg, J.: Water-vapor, condensed Water, and crystal concentration in orographically influenced cirrus clouds, J. Atmos. Sci., 51, 2368-2383, 1994.

Ström, J., Strauss, B., Anderson, T., Schroder, F., Heintzenberg, J., and Wendling, P.: In situ observations of the microphysical properties of young cirrus clouds, J. Atmos. Sci., 54, 2542-2553, 1997.

Ström, J. and Ohlsson, S.: In situ measurements of enhanced crystal number densities in cirrus clouds caused by aircraft exhaust, J. Geophys. Res., 103, 11355-11361, 1998.

Ström, J. and Ohlsson, S.: Real-time measurement of absorbing material in contrail ice using a counterflow virtual impactor, J. Geophys. Res., 103, 8737-8741, 1998.

Ström, J., Seifert, M., Kärcher, B., Ovarlez, J., Minikin, A., Gayet, J. F., Krejci, R., Petzold, A., Auriol, F., Haag, W., Busen, R., Schumann, U., and Hansson, H. C.: Cirrus cloud occurrence as function of ambient relative humidity: a comparison of observations obtained during the INCA experiment, Atmos. Chem. Phys., 3, 1807-1816, 2003, http://www.atmos-chem-phys.net/3/1807/2003/.

Textor, C., Schulz, M., Guibert, S., Kinne, S., Balkanski, Y., Bauer, S., Berntsen, T., Berglen, T., Boucher, O., Chin, M., Dentener, F., Diehl, T., Easter, R., Feichter, H., Fillmore, D., Ghan, S., Ginoux, P., Gong, S., Kristjansson, J. E., Krol, M., Lauer, A., Lamarque, J. F., Liu, X., Montanaro, V., Myhre, G., Penner, J., Pitari, G., Reddy, S., Seland, O., Stier, P., Takemura, T., and Tie, X.: Analysis and quantification of the diversities of aerosol life cycles within AeroCom, Atmos. Chem. Phys., 6, 1777-1813, 2006, http://www.atmos-chem-phys.net/6/1777/2006/.

Tiedtke, M.: Representation of clouds in large-scale models, Mon. Weather Rev., 121, 3040-3061, 1993.

Tompkins, A. M., Gierens, K., and Radel, G.: Ice supersaturation in the ECMWF integrated forecast system, Quart. J. Roy. Meteor. Soc., 133, 53-63, 2007.

Waliser, D. E., Li, J. L. F., Woods, C. P., Austin, R. T., Bacmeister, J., Chern, J., Del Genio, A., Jiang, J. H., Kuang, Z. M., Meng, H., Minnis, P., Platnick, S., Rossow, W. B., Stephens, G. L., SunMack, S., Tao, W. K., Tompkins, A. M., Vane, D. G., Walker, C., and $\mathrm{Wu}, \mathrm{D}$.: Cloud ice: A climate model challenge with signs and expectations of progress, J. Geophys. Res., 114, D00A21, doi:10.1029/2008JD0100152009.

Wang, P. H., Minnis, P., McCormick, M. P., Kent, G. S., and Skeens, K. M.: A 6-year climatology of cloud occurrence frequency from stratospheric aerosol and gas experiment II observations (19851990), J. Geophys. Res., 101, 29407-29429, 1996.

Wang, M. and Penner, J. E.: Aerosol indirect forcing in a global model with particle nucleation, Atmos. Chem. Phys., 9, 239-260, 
2009, http://www.atmos-chem-phys.net/9/239/2009/.

Wang, M. H., Penner, J. E., and Liu, X. H.: Coupled IMPACT aerosol and NCAR CAM3 model: Evaluation of predicted aerosol number and size distribution, J. Geophys. Res., 114, D06302, doi:10.1029/2008jd010459, 2009.

Weng, F. Z., and Grody, N. C.: Retrieval of cloud liquid water using the Special Sensor Microwave Imager (SSM/I), J. Geophys. Res., 99, 25535-25551, 1994.

Wu, X. Q.: Effects of ice microphysics on tropical radiativeconvective-oceanic quasi-equilibrium states, J. Atmos. Sci., 59, 1885-1897, 2002.

Wu, D. L., Jiang, J. H., and Davis, C. P.: EOS MLS cloud ice measurements and cloudy-sky radiative transfer model, Ieee Trans. Geosci. Remote Sens., 44, 1156-1165, 2006.

Wu, D. L., Austin, R. T., Deng, M., Durden, S. L., Heymsfield, A. J., Jiang, J. H., Lambert, A., Li, J.-L., Livesey, N. J., McFarquhar, G. M., Pittman, J. V., Stephens, G. L., Tanelli, S., Vane, D. G., and Waliser, D. E.: Comparisons of global cloud ice from MLS, CloudSat, and correlative data sets, J. Geophys. Res., 114, D00A24, doi:10.1029/2008JD009946, 2009.
Wylie, D. P. and Menzel, W. P.: Eight years of high cloud statistics using HIRS, J. Climate, 12, 170-184, 1999.

Wylie, D., Jackson, D. L., Menzel, W. P., and Bates, J. J.: Trends in global cloud cover in two decades of hirs observations, J. Climate, 18, 3021-3031, 2005.

Xie, S. C., Boyle, J., Klein, S. A., Liu, X. H., and Ghan, S.: Simulations of Arctic mixed-phase clouds in forecasts with CAM3 and AM2 for M-PACE, J. Geophys. Res., 113, D04211, doi:10.1029/2007JD009225, 2008.

Zhang, M. H., Lin, W. Y., Bretherton, C. S., Hack, J. J., and Rasch, P. J.: A modified formulation of fractional stratiform condensation rate in the NCAR Community Atmospheric Model (CAM2), J. Geophys. Res., 108, 4035, doi:10.1029/2002JD002523, 2003.

Zobrist, B., Koop, T., Luo, B. P., Marcolli, C., and Peter, T.: Heterogeneous ice nucleation rate coefficient of water droplets coated by a nonadecanol monolayer, J. Phys. Chem. C, 111, 2149-2155, doi:10.1021/Jp066080w, 2007. 